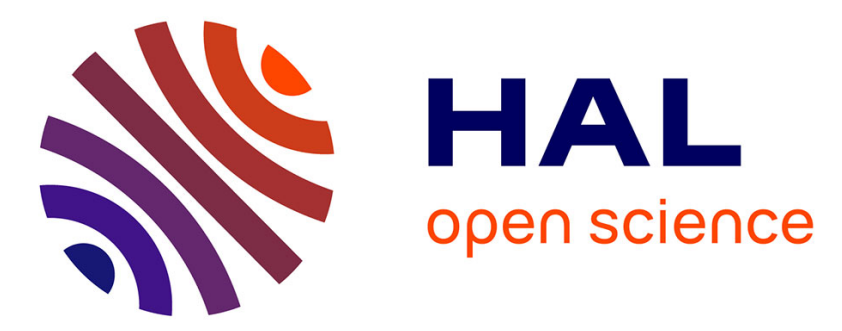

\title{
Urban thermodynamic island in a coastal city analysed from an optimized surface network
}

Grégoire Pigeon, Aude Lemonsu, Nathalie Long, Joël Barrié, Valéry Masson, Pierre Durand

\section{- To cite this version:}

Grégoire Pigeon, Aude Lemonsu, Nathalie Long, Joël Barrié, Valéry Masson, et al.. Urban thermodynamic island in a coastal city analysed from an optimized surface network. Boundary-Layer Meteorology, 2006, 120 (2), pp.315-351. 10.1007/s10546-006-9050-z . hal-00138643

\section{HAL Id: hal-00138643 https://hal.science/hal-00138643}

Submitted on 9 Sep 2021

HAL is a multi-disciplinary open access archive for the deposit and dissemination of scientific research documents, whether they are published or not. The documents may come from teaching and research institutions in France or abroad, or from public or private research centers.
L'archive ouverte pluridisciplinaire HAL, est destinée au dépôt et à la diffusion de documents scientifiques de niveau recherche, publiés ou non, émanant des établissements d'enseignement et de recherche français ou étrangers, des laboratoires publics ou privés. 


\title{
URBAN THERMODYNAMIC ISLAND IN A COASTAL CITY ANALYSED FROM AN OPTIMIZED SURFACE NETWORK
}

\author{
GRÉGOIRE PIGEON, ${ }^{1, *}$ AUDE LEMONSU ${ }^{1}$, NATHALIE LONG ${ }^{2}$, JOËL \\ BARRIÉ $^{1}$, VALÉRY MASSON ${ }^{1}$ and PIERRE DURAND ${ }^{3}$ \\ ${ }^{1}$ Centre National de Recherches Météorologiques, Météo-FrancelCNRS-GAME, 42 av. \\ Coriolis, 31057 Toulouse Cedex, France; ${ }^{2}$ GREYC - CNRS UMR 6072, Caen, France; \\ ${ }^{3}$ Laboratoire d'Aérologie, UMR CNRS-UPS 5560, Toulouse, France
}

\begin{abstract}
Within the framework of ESCOMPTE, a French experiment performed in June and July 2001 in the south-east of France to study the photo-oxidant pollution at the regional scale, the urban boundary layer (UBL) program focused on the study of the urban atmosphere over the coastal city of Marseille. A methodology developed to optimize a network of 20 stations measuring air temperature and moisture over the city is presented. It is based on the analysis of a numerical simulation, performed with the non-hydrostatic, mesoscale Meso-NH model, run with four nested-grids down to a horizontal resolution of $250 \mathrm{~m}$ over the city and including a specific parametrization for the urban surface energy balance. A three-day period was modelled and evaluated against data collected during the preparatory phase for the project in summer 2000 . The simulated thermodynamic surface fields were analysed using an empirical orthogonal function (EOF) decomposition in order to determine the optimal network configuration designed to capture the dominant characteristics of the fields. It is the first attempt of application of this kind of methodology to the field of urban meteorology. The network, of 20 temperature and moisture sensors, was implemented during the UBL-ESCOMPTE experiment and continuously recorded data from 12 June to 14 July 2001. The measurements were analysed in order to assess the urban thermodynamic island spatio-temporal structure, also using EOF decomposition. During nighttime, the influence of urbanization on temperature is clear: the field is characterized by concentric thermo-pleths around the old core of the city, which is the warmest area of the domain. The moisture field is more influenced by proximity to the sea and airflow patterns. During the day, the sea breeze often moves from west or south-west and consequently the spatial pattern for both parameters is characterized by a gradient perpendicular to the shoreline. Finally, in order to assess the methodology adopted, the spatial structures extracted from the simulation of the 2000 preparatory campaign and observations gathered in 2001 have been compared. They are highly correlated, which is a relevant validation of the methodology proposed. The relations between these spatial structures and geographical characteristics of the site have also been studied. High correlations between temperature spatial structure during nighttime and urban cover fraction or street aspect ratio are observed and simulated. For temperature during daytime or moisture during both daytime and nighttime these geographical factors are not correlated with thermodynamic fields spatial structures.
\end{abstract}

Keywords: Coastal city, EOF, Surface network, UBL-ESCOMPTE, Urban heat isand.

* E-mail: gregoire.pigeon@meteo.fr 


\section{Introduction}

The urban thermodynamic island (UTI) includes modifications concerning atmospheric thermodynamic parameters (temperature, moisture, pressure) over urban areas in comparison with rural areas around them. The urban canopy heat island (UHI) is the most studied effect of urban areas (see review in Arnfield 2003), and is characterized by higher air temperatures in the urban canopy in comparison to air temperatures over rural areas around a city. The temperature difference is generally amplified during nighttime, when winds are light and the sky is clear (Oke, 1987). The effect of urban areas on moisture has also been studied. During daytime, relative humidity and water vapour content are generally lower in urban areas. At night, urban areas can be considered drier if we regard relative humidity only, whereas water vapour content may be higher when dew deposition occurs in rural areas (Hage, 1975; Holmer and Eliasson, 1999). Evidence of these features of the UTI has been shown by field studies using fixed weather stations or mobile measurements from cars. High resolution numerical models have also been developed to describe urban effects (Masson, 2000; Lemonsu and Masson, 2002; Martilli et al., 2002; Dupont et al., 2004; Lemonsu et al., 2004). Parametrization of the urban surface energy balance in these models has been evaluated against field measurements, as with the town energy balance (TEB, Masson, 2000) model in Masson et al. (2002). But the urban schemes have rarely been used in mesoscale atmospheric simulations to study the spatio-temporal structure of the UTI in a real city, and they have never been used to optimize the design of an urban surface network. This is precisely the objective of our study for the coastal city of Marseille (France). The network measuring air temperature and relative humidity was then deployed during the field phase of the urban boundary layer (UBL) project (Mestayer et al., 2005) in June and July 2001. UBL was a part of ESCOMPTE, a program focused on the study of photochemistry and dispersion of pollutants over a region of about $100 \mathrm{~km}$ around Marseille city and Berre pond (Cros et al., 2004). During the preparatory phase of ESCOMPTE, a preliminary experiment was conducted during summer 2000 to test a large number of instruments and to validate the experimental strategy. A three-day Intensive Observation Period (IOP) of this field campaign was simulated with the non-hydrostatic, Meso-NH (Lafore et al., 1998) numerical model, with four nested grids to achieve a horizontal resolution as fine as $250 \mathrm{~m}$ over Marseille, and using the TEB parametrization for urban surfaces. Once the mesoscale simulation was evaluated against the observational dataset, the finest resolution fields were analysed to optimize the network spread in order to retrieve the main features of the UTI characteristics. A comparable strategy was used by Vihma and Kottmeir (2000) to optimize flight 
plans from numerical modelling approaches, in order to capture with a limited number of runs most of the variance of the atmospheric fields.

Herein, we present the different steps of the method to optimize the network design. First, the numerical simulation is described and evaluated against observations conducted during the preliminary campaign in summer 2000. Then, we demonstrate how the simulation output was used to define a network organization using empirical orthogonal functions (EOFs) decomposition. The final step of the method is a verification of the ability of the network to retrieve the main features of the thermodynamic fields over Marseille. The 20 locations for the sensors were extracted from the simulation and EOFs were computed on these data and compared to the EOF computed on the whole domain of the simulation. The dataset gathered during the summer 2001 ESCOMPTE campaign is also analysed using EOF decomposition to assess the characteristics of the Marseille UTI. Finally, relations between thermodynamic fields and local surface characteristics are studied in both observations and simulation.

\section{Experimental Site}

Marseille $\left(43^{\circ} 18^{\prime} \mathrm{N}, 5^{\circ} 23^{\prime} \mathrm{E}\right)$ is located in south-east of France, and is bordered westward and southward by the Mediterranean sea (Figure 1). At a horizontal scale of about $100 \mathrm{~km}$, the coast is oriented west-northwest/east-south-east. The hills of the Massif de l'Etoile $(670 \mathrm{~m})$ are located to the north and east of the city, the Massif de l'Estaque $(270 \mathrm{~m})$ to the north-west, Mont Carpiagne $(647 \mathrm{~m})$ and Mont Puget $(564 \mathrm{~m})$ to the southeast and finally the Massif de Marseilleveyre $(433 \mathrm{~m})$ to the south. This topography results in a complex dynamical forcing that strongly influences the airflow patterns over the city (Lemonsu et al., 2005). The climate of the region is Mediterranean, and during summer the weather is typically sunny with maximum air temperatures of $30-35^{\circ} \mathrm{C}$ inland and $25-30^{\circ} \mathrm{C}$ at the coast. South-west sea breezes are frequently observed over the agglomeration. The Mistral (a north-west wind) and south-east winds can also affect the city during summer.

About one million inhabitants live in the city and the surrounding suburbs. The urban structure (Figure 1) is determined by the presence of the sea: the old city centre concentrates around the harbour, the so-called 'Vieux Port'. Thus the most densely urbanized zones are located on the west coast and extend about $3 \mathrm{~km}$ northwards, eastwards and southwards. Further inland, the urban density progressively decreases although localized patches of high density urban land-use are often located in the valleys to the north and east of the city. In the city centre, the streets are narrow and the building height is about $15 \mathrm{~m}$. The urban fabric of the 


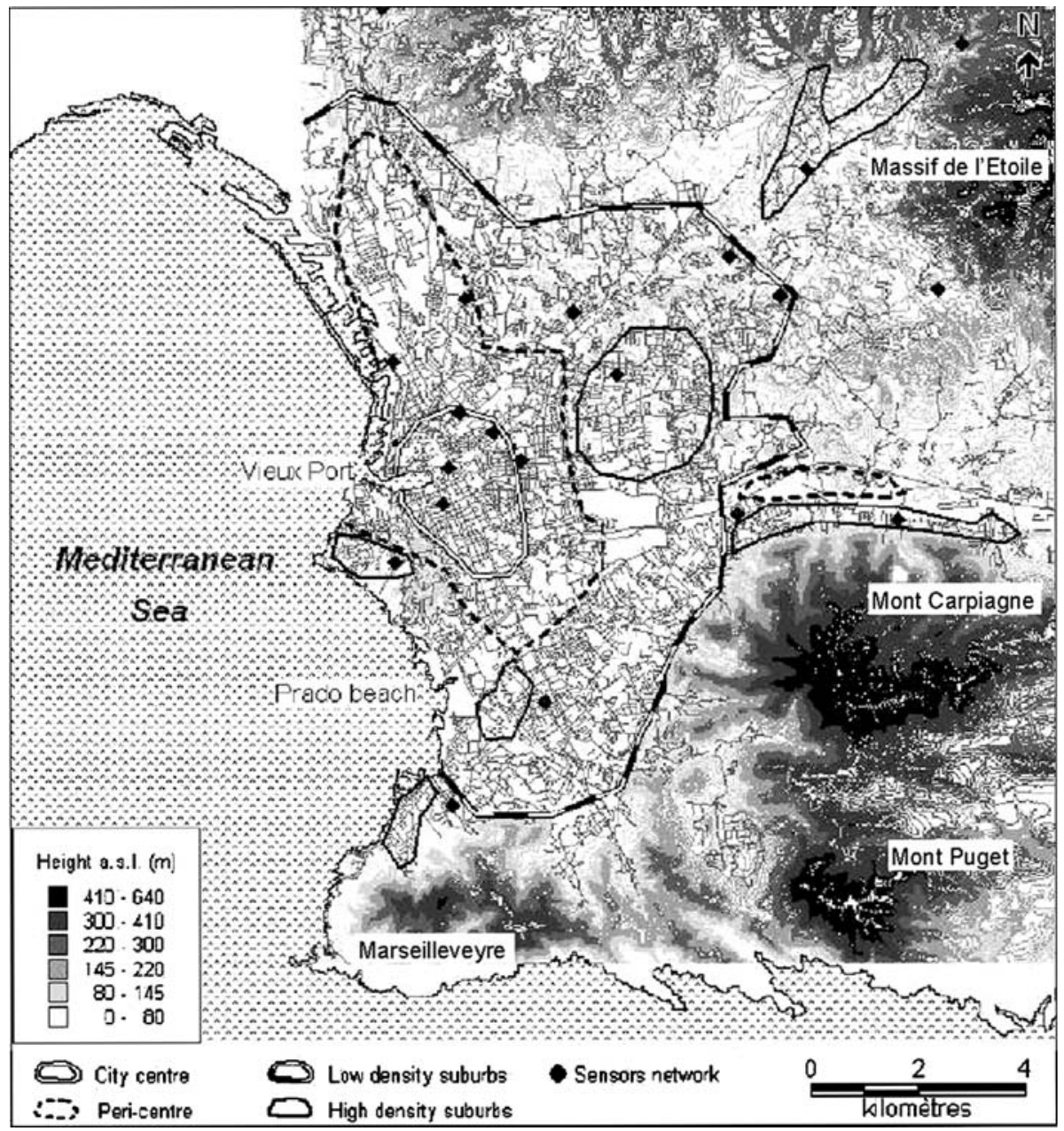

Figure 1. Orography of the Marseille agglomeration.

southern part of the city is more heterogeneous with smaller buildings and more vegetation inside private or public gardens. North and east of the city, the urbanization is also heterogeneous with small houses and a few areas of multi-storey buildings. There is little vegetation on the hills.

\section{Numerical Simulation}

\subsection{PERIOD OF SIMUlation}

The preliminary ESCOMPTE campaign was conducted from 19 June to 9 July 2000. This modelling study focuses on the IOP from 29 June to 1 July ('IOP 0 '), during which a succession of different wind conditions 
prevailed. On 29 June, north-north-west to north-west winds associated with the Mistral were observed over the whole domain and abated in the first part of the night. The next day, the north-west wind was moderate in the morning and then shifted to the west. A sea breeze developed in the afternoon, especially over Marseille city. The last day was characterized by a southerly flow. Therefore, the prevailing regional mesoscale flows were observed during these 3 days. Clear sky conditions were observed during the IOP, except on the morning of 1 July.

\subsection{Presentation of the nUMerical Simulation}

The simulation is performed with the Meso-NH non-hydrostatic atmospheric model (Lafore et al., 1998). Four two-way, grid-nested models (whose domains are presented in Figure 2) are used in order to reach a high resolution for the last domain centred on the city of Marseille. The horizontal resolution of these grids is $12,3,1 \mathrm{~km}$ and $250 \mathrm{~m}$, respectively.
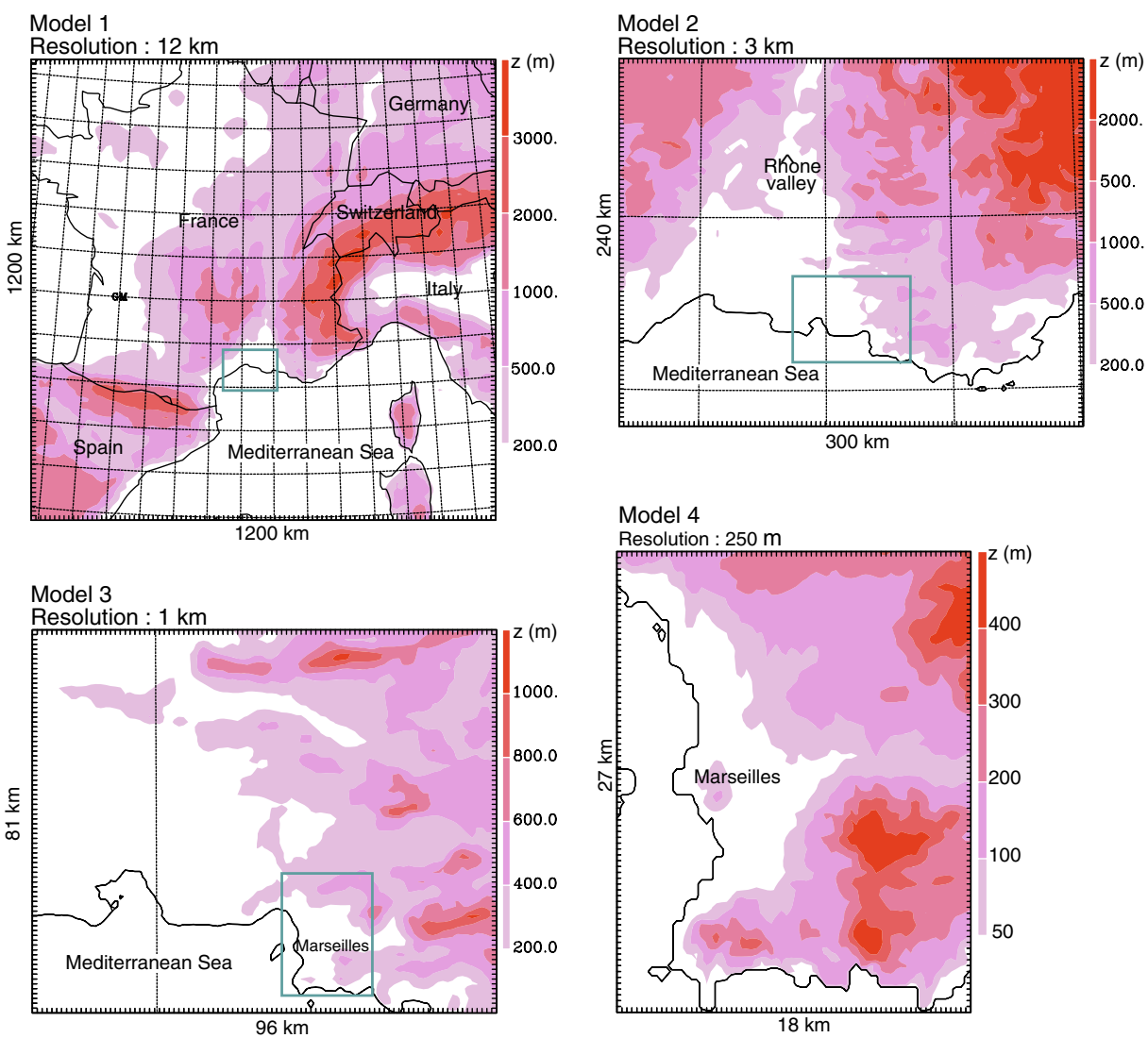

Figure 2. The grid-nested modelling domains and terrain elevation. 
For all the models, the vertical coordinate is composed of 52 levels stretched according to altitude from 20 to $16,000 \mathrm{~m}$. Fifteen levels are located in the first $1000 \mathrm{~m}$ to finely resolve boundary-layer processes. By applying the two-way grid-nesting method, information between two successive models is exchanged at every timestep. The initial and boundary conditions of the first domain are defined from European Center for Medium-Range Weather Forecasts (ECMWF) analyses; the boundary conditions are reinitialized every $6 \mathrm{~h}$. The ECMWF scheme is used for radiative transfer (Morcrette, 1991), and a warm Kessler (1969) microphysical parametrization is applied for three classes of water: vapour, cloud water and rain. Finally, the mixing length is computed according to the Bougeault and Lacarrère (1989) scheme for the first three models and to Deardorff (1970) method for the last model. Only vertical diffusion is taken into account in models 1 and 2, whereas a three-dimensional (3D) scheme (Cuxart et al., 2000) is used for the last two models.

The Meso-NH model is coupled to the TEB (Masson, 2000) and Interaction Soil Biosphere Atmosphere (ISBA, Noilhan and Planton, 1989) surface schemes (Figure 3). This configuration has been used by Lemonsu and Masson (2002) and Lemonsu et al. (2006). ISBA parametrizes the exchanges between the atmosphere and natural or agricultural land covers, and is described in detail in Noihan and Mahfouf (1996). The TEB scheme (Masson, 2000; Masson et al., 2002) is dedicated to the built surfaces, and

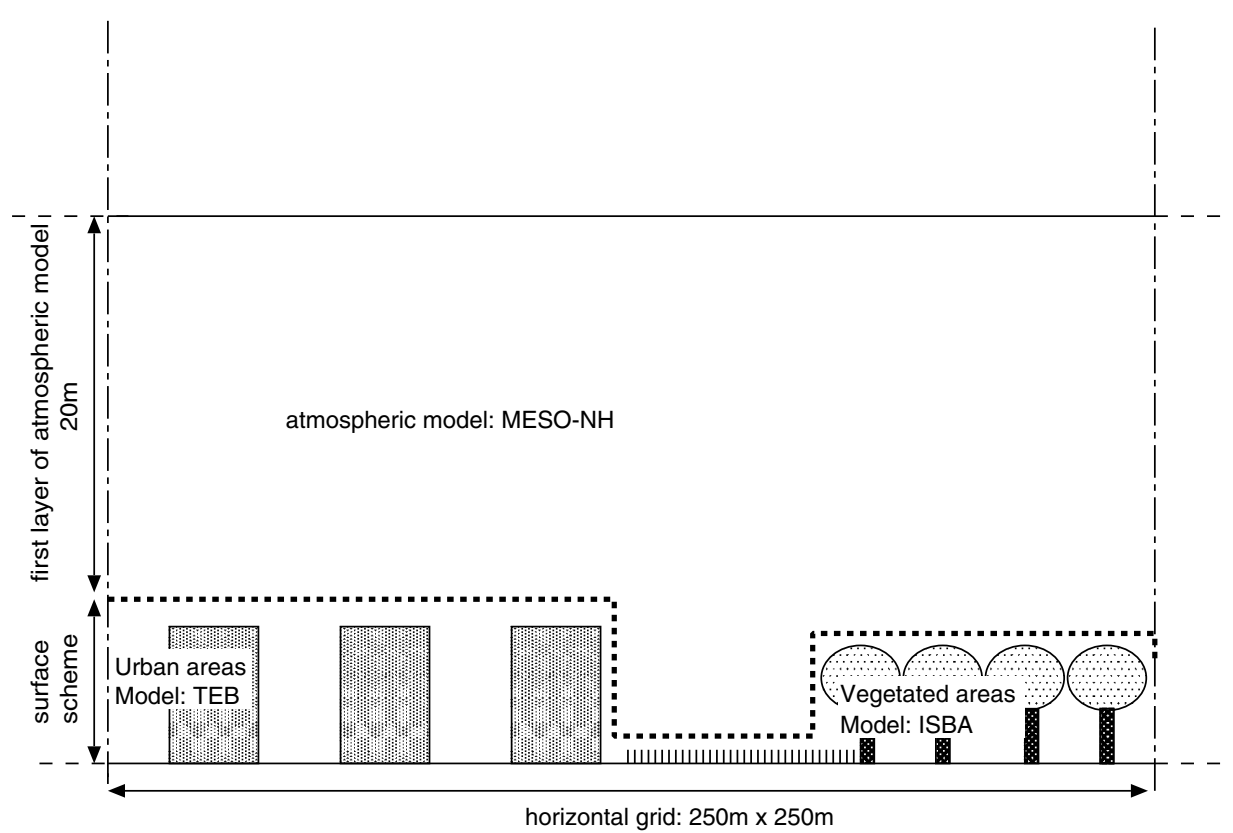

Figure 3. Presentation of the lowest levels of the model and the surface schemes used. 
because of a simplified but realistic parametrization of urban 3D geometry, interactions between roads, roofs, walls and the atmosphere can be physically resolved. Both surface schemes need an accurate description of the soil occupation to define the initial parameters; the Ecoclimap surface parameter database (Masson et al., 2003) at 1-km horizontal resolution is used for models 1 and 2. The land cover is based on the CORINE land-cover classification (CEC, 2000), which provides for Europe 44 classes, among which 11 are urban classes, at 1-km resolution. A $250-\mathrm{m}$ resolution database, built in 1989 and focusing on the Marseille region is applied to models 3 and 4 . Consequently, the numerical representation reproduces the complexity of the experimental area by accounting for topography, sea area and the urban surface. The simulation of the three successive days (from 29 June to 1 July 2000) is made without any re-initialization except at the borders of the first domain. For the smallest grid, air temperature at $6 \mathrm{~m}$ height in the atmospheric model was computed using a surface-layer formulation; this corresponds with the decision to install the instruments at this height as being representative of the urban canopy layer (Nakamura and Oke, 1988). Such a recommendation is also given by Oke (2004) in guidelines for the World Meteorological Organization; the choice will be discussed later in Section 4.3.

\subsection{Evaluation of the Meso-NH Simulation}

One of our objectives is to exploit the simulation in order to optimize the design of a surface network. An important step is therefore a thorough comparison and evaluation of the simulation against observations. The available data for the preliminary campaign are: surface observations and documentation of the vertical structure of the atmosphere with radiosondes, remote-sensing instruments and aircraft flights. Furthermore, 23 stations in the operational network of Météo-France are selected, two of them being located inside the agglomeration of Marseille; they continuously record air temperature and relative humidity at $2 \mathrm{~m}$, and wind direction and velocity at $10 \mathrm{~m}$. The location of these instruments is presented in Figure 4. The comparison is done mainly with the fields of model 2 (with a horizontal resolution of $3 \mathrm{~km}$ ). The first level of evaluation concerns the regional forcing on which depends the quality of the simulation at the local scale. Then, the second level of evaluation is a verification of the ability of the model to reproduce the spatial variability of thermodynamic fields over the agglomeration of Marseille. This step, limited because of the few stations available in Marseille during this period, will be completed a posteriori by a comparison with the data collected by the network in 2001 (see Section 6). 


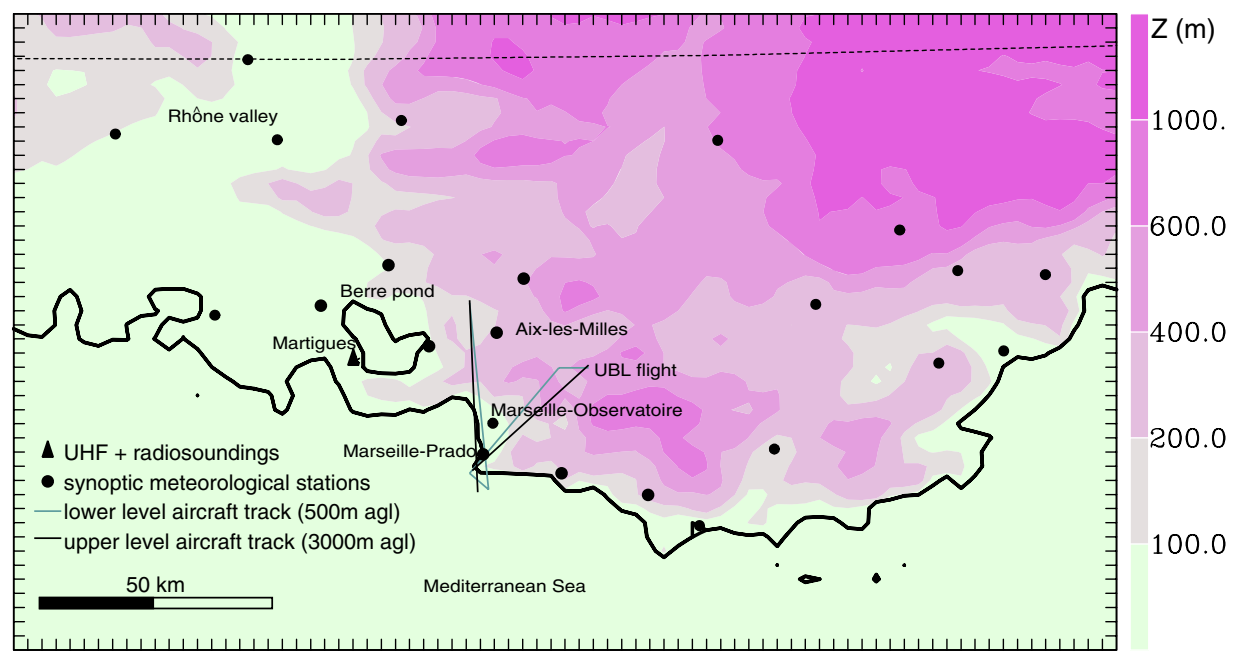

Figure 4. Location of instruments during ESCOMPTE preparatory campaign (June-July 2000) and terrain elevation.

\subsubsection{Evaluation of Regional Forcing}

3.3.1.1. Surface parameters. In the model, the first atmospheric level is at $20 \mathrm{~m}$ above the canopy, but the 2-m air temperature and specific humidity are computed from the simulation output using surface-layer formulations. The comparisons between the simulation and the observations are presented in Figure 5; upper graphs represent the average of measurements or simulation at the 23 stations of Météo France. The lower graphs represent the root mean square (rms) of the difference between the simulation and observations. On average, the simulation and the observations are close. The increase of moisture over the whole domain is well reproduced in the simulation, while the diurnal cycle of temperature is overestimated by about $2^{\circ} \mathrm{C}$ on the last 2 days. This is also the order of the mean difference between observations and simulation as can be seen in the temperature rms (Figure 5). The mean difference for moisture is between 1 and $2 \mathrm{~g} \mathrm{~kg}^{-1}$. Though not perfect, these comparisons can be viewed as satisfying, because measurements at the ground stations are representative of a small area around the station ('footprint'), and the heterogeneity could be large inside a $3 \mathrm{~km} \times 3 \mathrm{~km}$ model mesh.

\subsubsection{Wind profile. A UHF Doppler radar from Météo-France was} installed at Martigues close to the Berre pond (Figure 4) to measure the vertical profile of horizontal wind. The measurements clearly show the successive wind conditions described in Section 3.1 (Figure 6). Meso-NH succeeds in simulating the Mistral situation during the first day, the rotation of the wind from north-west to south-west on 30 June, and finally to south on 1 July. 

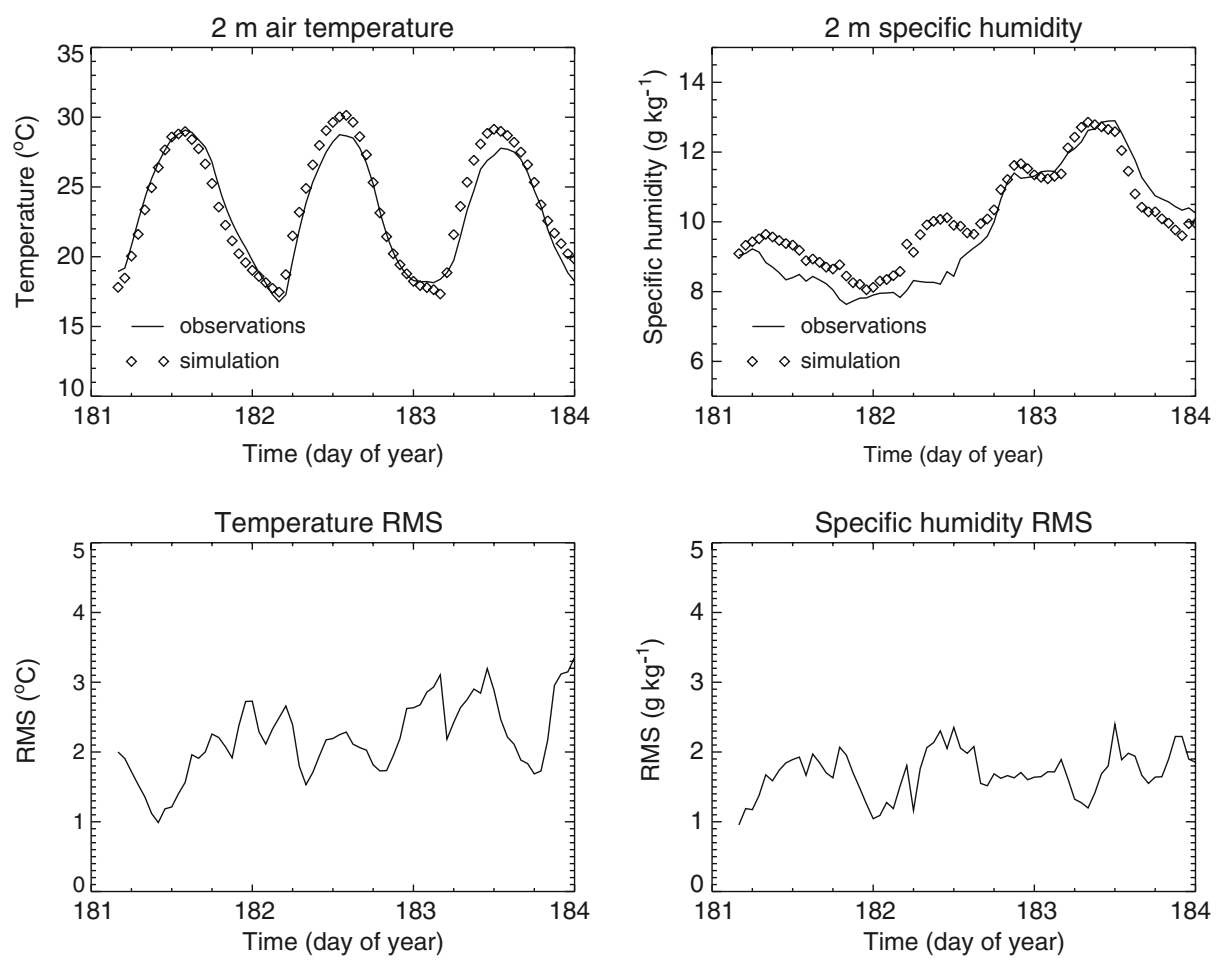

Figure 5. Comparison between averaged temperature and specific humidity at $2 \mathrm{~m}$ measured at 23 stations of the operational network (see Figure 4 for location), and the average over the 23 corresponding grid points of the model 2 .

The wind velocity is well simulated from the end of 29 June to the morning of 1 July. But then, on 1 July, the wind speed simulated by the model is greater than the observations: the simulation computes a wind velocity of $10-12 \mathrm{~m} \mathrm{~s}^{-1}$ between 1200 and 1700 UTC for all levels while the radar measures a speed of $5-7 \mathrm{~m} \mathrm{~s}^{-1}$ at $400 \mathrm{~m}$ and less than $2 \mathrm{~m} \mathrm{~s}^{-1}$ at $700 \mathrm{~m}$ for the same hours. A radiosonde released at the same location at 1100 UTC confirms the radar observations since it records a speed of $2.5-5 \mathrm{~m} \mathrm{~s}^{-1}$ between the ground and $1500 \mathrm{~m}$ above sea level (a.s.l.) (Bénech et al., 2001). To explain this disagreement with the model, one can note that the radar or the radiosonde observe locally in the vertical at their location or launching site while the model has a mesh of $3 \mathrm{~km} \times 3 \mathrm{~km}$. Furthermore, a constant volume, drifting balloon, also released at Martigues at 1240 UTC and floating at $750 \mathrm{~m}$ a.s.l. records wind speeds of $7-10 \mathrm{~m} \mathrm{~s}^{-1}$ during the first part of its horizontal flight (Bénech et al., 2001). This record, which is in good agreement with the simulation, is very interesting since it has been provided by a device that integrates measurements on length scales comparable with the mesh size of the model. This final element allows us to conclude that the simulation of the wind at the regional scale is satisfactory. 

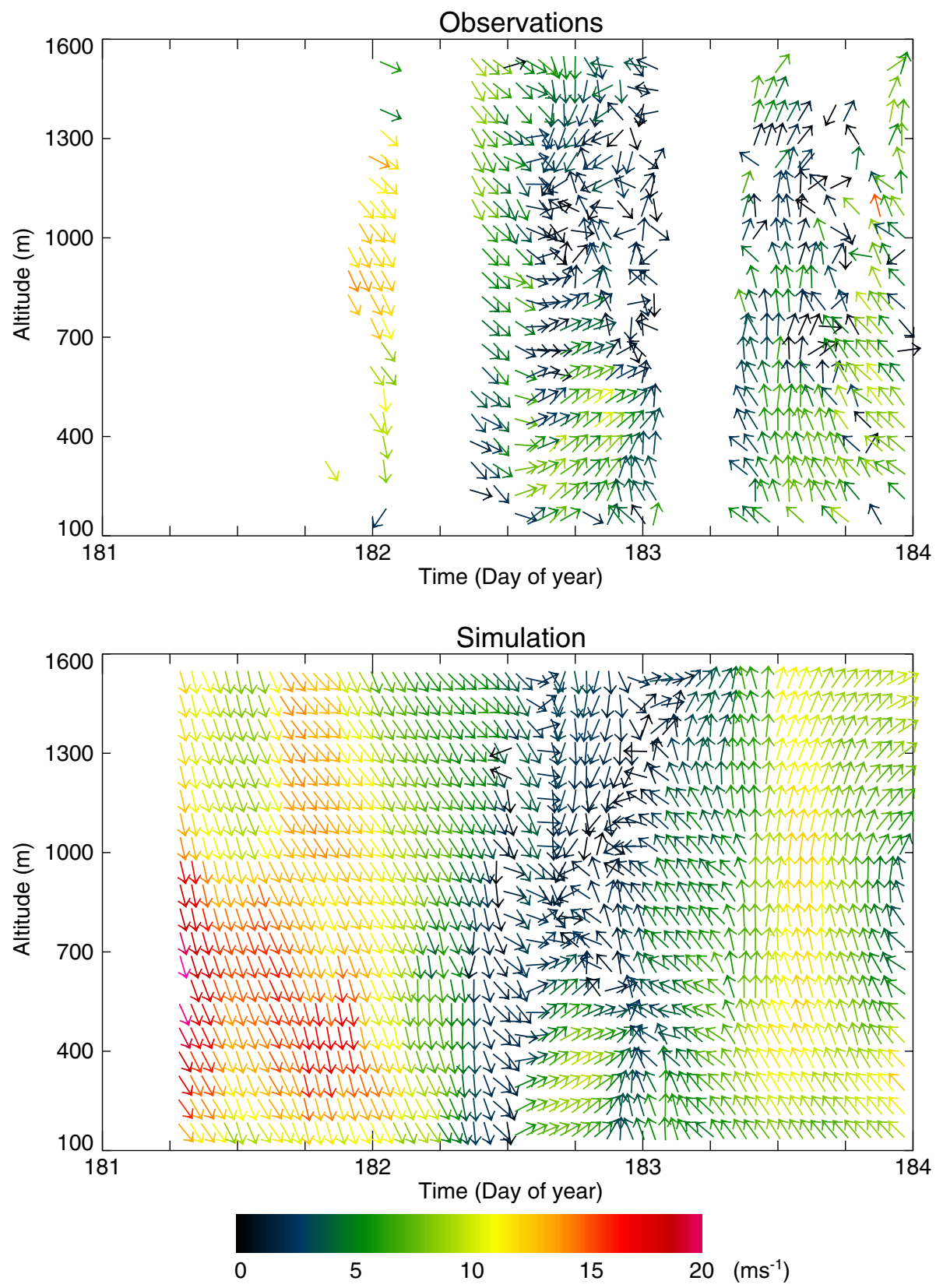

Figure 6. Time-height cross-section of the horizontal wind (top: observations; bottom: model). Arrows indicate the wind direction. Colour represents wind strength. 

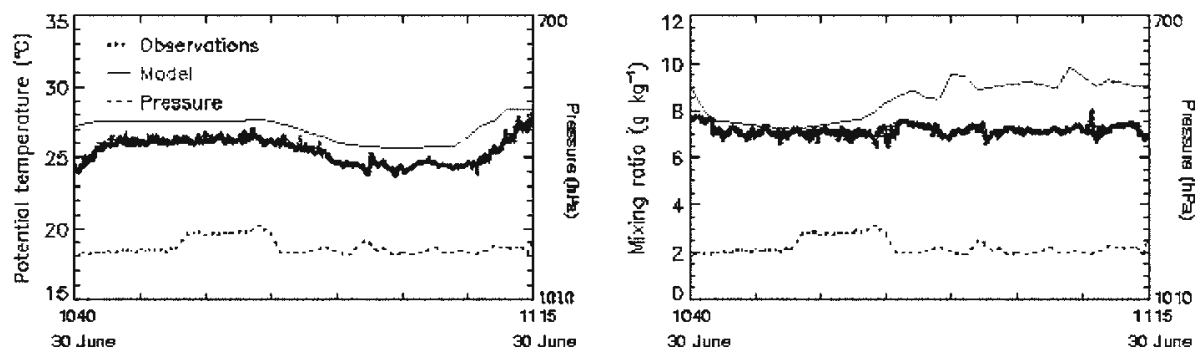

Figure 7. Validation of model output against the measurements from the flight over Marseille. The dotted line is the time series of aircraft pressure level.

3.3.1.3. Vertical structure of the atmospheric boundary layer. Radiosondes were launched at Martigues (see Figure 4), three or four times each day. The potential temperature and specific humidity profiles indicate a multilayered organization (Bénech et al., 2001), a structure that is a consequence of the geographic complexity of the launching site, which is surrounded by the Berre pond, the sea and hills. The different layers correspond to different airflow patterns. The model generally reproduces similar structures (not presented). Finally, two instrumented aircraft flew according to specific trajectories to document the different dynamical situations. Here only the results from the flight over Marseille on the 30 June, starting at 1040 UTC, are presented. The Piper Aztec 23 of Météo-France flew at a level of $500 \mathrm{~m}$ a.g.1., inside the atmospheric boundary layer (ABL) (see the flight track on Figure 4). Potential temperature simulated along the aircraft track (see Figure 7) is overestimated inside the ABL by about $2{ }^{\circ} \mathrm{C}$, but the spatial variation is very well reproduced by the model, which is essential for the analysis of the spatio-temporal variability over Marseille. For moisture, the simulation computes the right level, but produces a spatial variability that is dissimilar to that during the flight, though the difference never exceeds $2 \mathrm{~g} \mathrm{~kg}^{-1}$.

\subsubsection{Evaluation of the Simulation at the City Scale}

Three stations have been selected among the preceding 23: MarseilleObservatoire, Marseille-Prado (the two stations are located inside parks in Marseille) and Aix-les-Milles (a rural station, $30 \mathrm{~km}$ to the north of Marseille). For the two stations inside Marseille, the output of model 4 (see Figure 2) has been extracted. The comparisons between the observations and the simulation for these three stations are presented in Figure 8 for air temperature (black) and specific humidity (grey).

For Marseille-Observatoire (left graph in Figure 8), the simulation reproduces the recorded observations during most of the period except on the first afternoon for specific humidity and the first night for temperature 

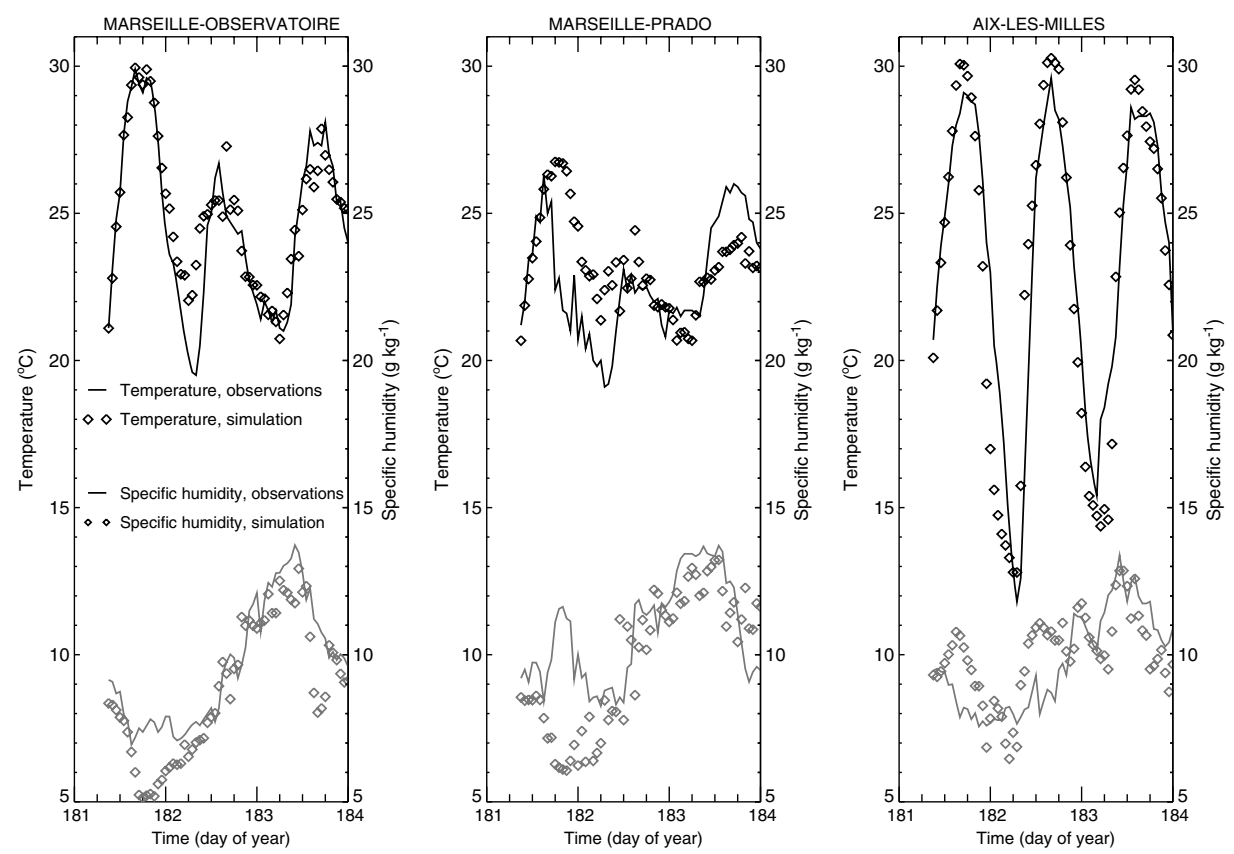

Figure 8. Comparison between observations and simulation of temperature (black) and specific humidity (grey) at $2 \mathrm{~m}$ for three locations: Marseille-Observatoire (left), Marseille-Prado (middle) and Aix-les-Milles (right).

(overestimation of $2^{\circ} \mathrm{C}$ ). Marseille-Prado (middle graph in Figure 8) is a station very close to the shoreline $(250 \mathrm{~m})$ and $5 \mathrm{~km}$ to the south-west of Marseille-Observatoire. Temperature measured at Marseille-Prado is lower than the temperature recorded at Marseille-Observatoire. The simulation reproduces well this difference, though the value of the daily peak is not exactly computed. On the first day, the observed temperature falls after the midday maximum while the simulation produces a more regular cycle. During the same time, the station observed humidity of $12 \mathrm{~g} \mathrm{~kg}^{-1}$ while the simulation computes drier air. On this day, with moderate north-west winds the air mass that passes over Marseille-Prado crosses the Marseille bay. In the model, the same phenomenon is simulated but is located more to the south of Marseille-Prado (not shown). On the last day, characterized by a south-east wind, the moisture evolution is well reproduced but the temperature is underestimated. Concerning Aix-les-Milles (right graph in Figure 8), the simulation reproduces a correct evolution and amplitude for temperature with a maximum difference with the observations of $1{ }^{\circ} \mathrm{C}$. For moisture, the model computes the right level and the right evolution during the period, even though details in the daily evolution are not reproduced.

We have computed the differences in temperature and moisture between Marseille-Observatoire and the two other stations to check the ability of 

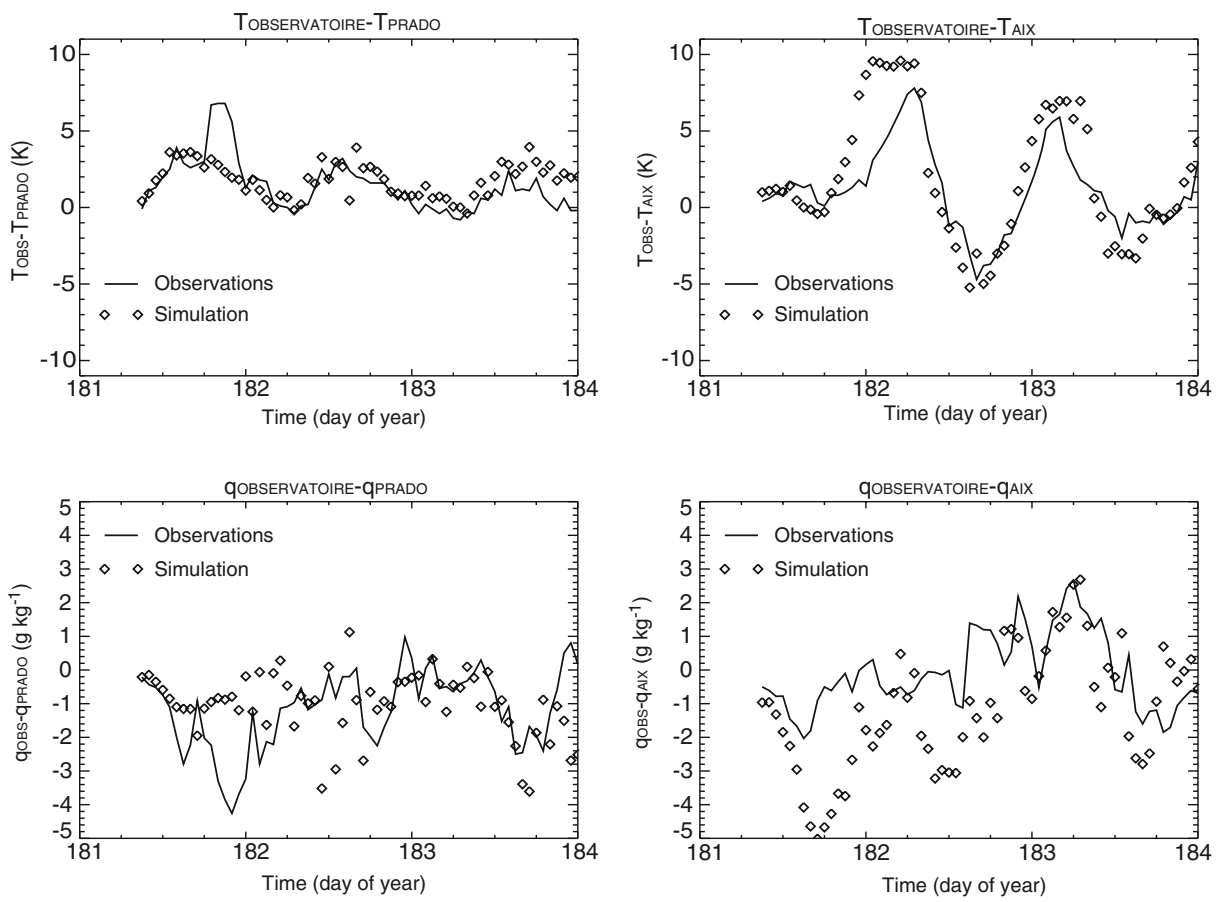

Figure 9. Comparison between observations and simulation of temperature and specific humidity difference between Marseille-Observatoire and Marseille-Prado (left) and Marseille-Observatoire and Aix-les-Milles (right).

the model to reproduce the spatial variability over the agglomeration of Marseille (Figure 9). The left graphs of Figure 9 present the comparison between observations and the simulation for the difference between Marseille-Observatoire and Marseille-Prado. For the temperature difference (upper graph), the simulation reproduces well the evolution between the two stations, which is marked by an increase around midday. For the moisture difference (lower graph) the model reproduces well the average value during the period, with the same level of variability.

The right-hand graphs of Figure 9 present the same comparison but for the difference between Marseille-Observatoire and Aix-les-Milles. The temperature difference is marked by negative values during daytime, resulting from the influence of the sea at the Marseille-Observatoire station associated with the wind conditions recorded during the period. During nighttime, the difference is positive corresponding to the development of the UHI. The simulation reproduces very well this cycle. For moisture the general tendency is computed by the simulation: the difference evolves from negative values during the first 2 days of the period to positive values on the night before the last day and finally comes back to negative values. 
This set of comparisons demonstrates the quality of the simulation. The regional forcing is well reproduced both at the surface and on the vertical in the ABL. At the city scale, the spatial variability between the few stations available on this domain is also well modelled. Consequently, the results of the simulation can be used to optimize the spreading of the network over Marseille.

\section{Analysis of the Simulation Output to Define the Network Disposition}

The method of empirical orthogonal function (EOF) decomposition is used to determine the spatio-temporal structure of the variability of two parameters of the simulation: air potential temperature $(\theta)$ and specific humidity $(q)$ at $6 \mathrm{~m}$ above the surface. The computation is done on the fields produced by the finest model (250-m resolution), on land areas (sea areas are excluded) whose altitude is lower than $250 \mathrm{~m}$, in order to reduce thermodynamic effects due to terrain elevation. A specific normalization of the EOFs is used (see Appendix A for details), so that values on the horizontal fields of the different components $\left(\mathrm{EOF}_{k}^{X}\right)$ lie between 0 and 1 , whereas the time series of one $\operatorname{EOF}\left(\triangle \mathrm{EOF}_{k}^{X}\right.$ according to Appendix $\mathrm{A}$ ) is the $\theta$ or $q$ difference between the two extreme points (i.e. of value 0 and 1) of the EOF horizontal field, and is expressed in units of $\mathrm{K}$ or $\mathrm{g} \mathrm{kg}^{-1}$, whether $X$ represents $\theta$ or $q$.

\subsection{Spatio-temporal Structure of POtential temperature}

For $\theta$, the EOF is computed for nighttime (2000 UTC to 0600 UTC) and daytime (0600 UTC to 2000 UTC). The spatial structure of the first EOF $\left(\mathrm{EOF}_{1}^{\theta}\right.$, see Appendix A for a precise definition) for daytime $\left(\mathrm{EOF}_{1}^{\theta}(\mathrm{day})\right)$ is presented in Figure 10. This spatial structure is associated with the time series $\left(\Delta \mathrm{EOF}_{1}^{\theta}\right)$ presented also in Figure $10 . \mathrm{EOF}_{1}^{\theta}$ (day) captures $63 \%$ of the spatio-temporal variability of potential temperature at $6 \mathrm{~m}$. On the $\mathrm{EOF}_{1}^{\theta}$ (day) spatial structure, the horizontal gradient is oriented north-east to south-west. When one compares spatial structure and urbanization density (white lines in Figure 10), no correlation appears between the two fields. The time series presents a repetitive evolution of the 3 days: the difference in $\theta$ (between north-east areas and south-west areas according to the spatial structure) increases in the morning, reaches a maximum in the afternoon and then decreases in the evening.

Figure 11 presents the spatial structure and temporal evolution of the first EOF for the nighttime temperature field $\left(\mathrm{EOF}_{1}^{\theta}\right.$ (night)), which captures $65 \%$ of spatio-temporal variability. The spatial structure of $\mathrm{EOF}_{1}^{\theta}$ (night) has a pattern similar to that of the urbanization density: the large area with 

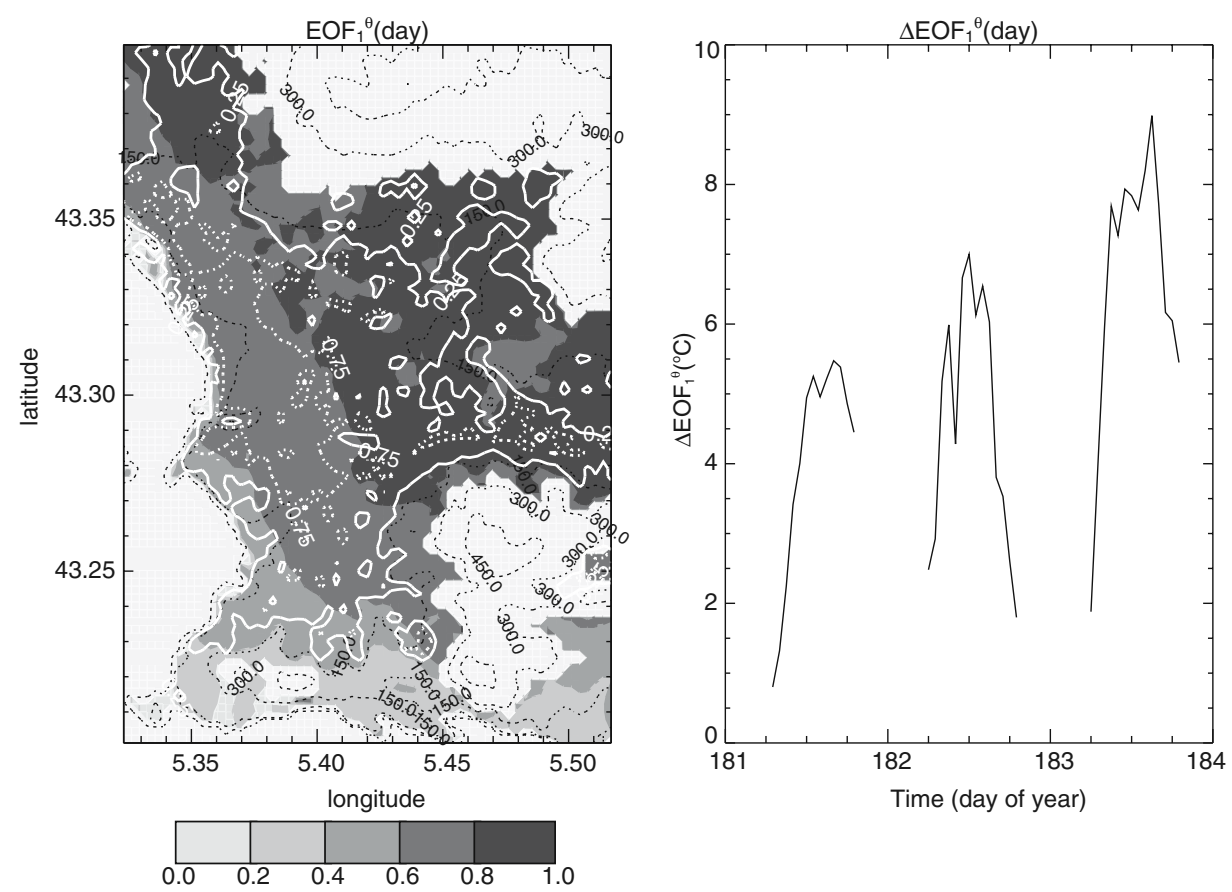

Figure 10. First EOF for $\theta$ during daytime, spatial structure (left) and temporal evolution (right). The white solid and dotted lines are the boundaries of the regions with planar area density of buildings and impervious soil higher than 0.25 and 0.75 , respectively.

values between 0.8 and 1.0 on the spatial structure is in the west of the domain where urbanization is the most dense. Considering the evolution of $\Delta \mathrm{EOF}_{1}^{\theta}$ (night), this area with high values of $\mathrm{EOF}_{1}^{\theta}$ (night) is warmer than the surroundings in the middle of the night. In this area, more than $80 \%$ of the surface is occupied by urbanized elements (dashed white line in Figure 11). It can also be noticed that the time series presents a similar evolution for the three different nights, in spite of the differences observed in the large-scale flows. Difference in temperature (between more and less urbanized areas) increases during the first part of the night, reaches a maximum at around 0200 UTC and then decreases, according to the classical evolution of UHI (Oke, 1987). Maximum values in the time series are about $9{ }^{\circ} \mathrm{C}$, and are surprisingly high, but we must take into account that they represent the difference between the two most different points of the entire field.

\subsection{SPATIO-TEMPoral STRUCTURE OF SPECIFIC HUMIDITY}

For $q$, the EOFs are computed for the entire simulation (from 29 June at 0700 UTC to 1 July 2000 at 2300 UTC), because no significant 

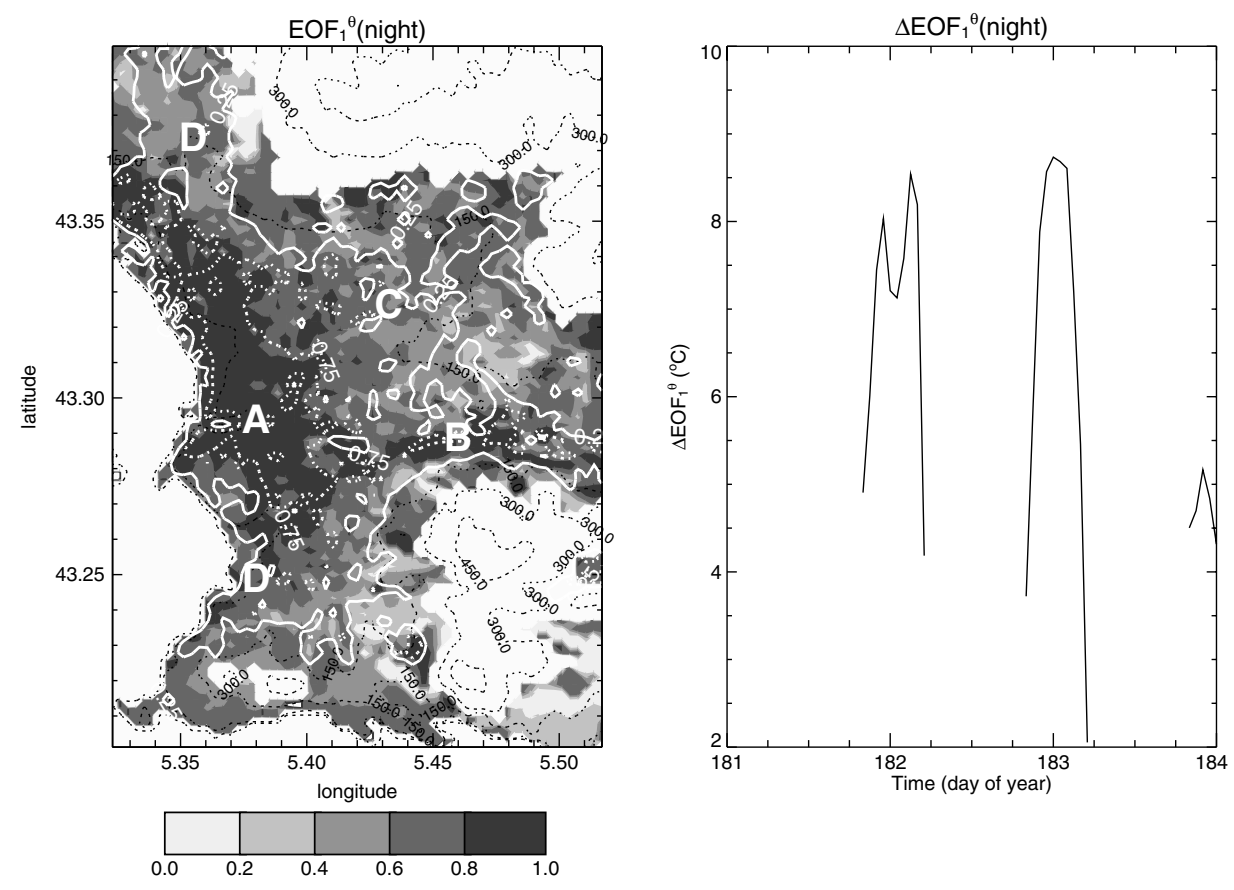

Figure 11. Same as Figure 10 but for $\theta$ during nighttime.

difference in spatio-temporal structure is found between daytime and nighttime. Figure 12 presents the spatial structure and temporal evolution of the first $\mathrm{EOF}$ for the whole simulation $\left(\mathrm{EOF}_{1}^{q}\right)$, and this captures $52 \%$ of the spatio-temporal variability of $q$. This is lower than for $\theta$. Horizontal gradients of $\mathrm{EOF}_{1}^{q}$ are oriented from north-east to south-west (i.e. opposed to the air temperature gradient for daytime). No repetitive structure in the time series can be found either for daytime or nighttime. The difference in $q$ sharply increases on the last day of the simulation when the wind is from the south-east. The southern areas, upwind of the orography (Figure 1), are characterized by higher specific humidity than downwind areas. Spatio-temporal pattern of $q$ over Marseille during this period results from the influence of local orography and air flow, but not from the urbanization structure.

\subsection{NETWORK DISPOSITION}

The instruments were placed in locations where air temperature or moisture could be representative of a scale larger than the street around the instrument. This choice was mainly based on results from Nakamura and Oke (1988) and Eliasson (1996), where both studies focused on the air temperature field inside a canyon. They showed that important gradients exist 
TABLE I

Intercomparison of sensors.

\begin{tabular}{lllllll}
\hline & \multicolumn{2}{c}{ Before the experiment } & & \multicolumn{2}{c}{ After the experiment } \\
\cline { 2 - 3 } \cline { 5 - 6 } & \multicolumn{2}{c}{$T\left({ }^{\circ} \mathrm{C}\right)$} & $\mathrm{RH}(\%)$ & & $T\left({ }^{\circ} \mathrm{C}\right)$ & $\mathrm{RH}(\%)$ \\
\hline Standard deviation & 0.08 & 0.75 & & 0.13 & 0.71 \\
Maximum difference & 0.20 & 3.23 & & 0.49 & 2.77 \\
\hline
\end{tabular}

$T$ : temperature; $R H$ : relative humidity.

close to walls or roads, but the difference between air temperature above and within the canyon is generally small $\left(<1^{\circ} \mathrm{C}\right)$. Thus, our concern was that the sensors were located away from walls and road surfaces and we therefore positioned these on electrical or trolley pylons at $6 \mathrm{~m}$ above the ground (Figure 15). The probes were placed in a radiation screen and set aside from the pylons on a boom of about $1.5 \mathrm{~m}$. The sensors (HygroClip from Rotronic) consisted of a platinum thermistor (100 $\Omega$ ) for temperature and a capacitive probe for moisture measurements. An intercomparison was made before and after the experiment. Results are given in Table I and are satisfying for both parameters, i.e. the accuracy was good enough to capture the principal structures of horizontal fields. The measurements were made every 10 minutes from 12 June to 14 July 2001.

To discuss the disposition of the network, we must first note that the network was composed of 20 stations installed at a fixed place for the whole campaign. Though each station could record temperature and moisture with a comfortable temporal resolution $(10 \mathrm{~min})$, their limited number (20) does not allow capture of the small-scale spatial variability. This is the reason why we focused on variations at the scale of the city (the distance between north-south borders of the domain presented in Figure 10 is $22 \mathrm{~km}$ ). Furthermore, the simulation is able to describe the horizontal fields for scales larger than $500 \mathrm{~m}$. The results of normalized EOFs are thus of major interest, because (1) they give the spatio-temporal pattern of most of the variance, and (2) they exhibit (at least for temperature) a repetitive behaviour for daytime and nighttime periods, which can thus be considered as representative of the UTI over Marseille. The disposition of the network had therefore to be decided in order to sample the spatial structures associated with these cycles. Since our aim is to study the impact of the urbanization on thermodynamic parameters of the urban atmosphere, the first spatio-temporal structure to sample is $\mathrm{EOF}_{1}^{\theta}$ (night) (Figure 11). This requires a disposition of stations that enables capture of the following characteristics found in the simulation output: 
- the warmer area situated in the old core of the city (A, in Figure 11) in comparison with surrounding areas,

- the extension of this warm area in the east valley (B, in Figure 11),

- the progressive decrease of temperature from the centre to north-east areas $(\mathrm{C}$, in Figure 11)

- areas cooler than the centre in the north and south of the centre $(\mathrm{D}$, in Figure 11).

Then the daytime cycle observed for $\mathrm{EOF}_{1}^{\theta}$ (day) must also be sampled even if there is no link with the urbanization; its recurrence shows that the $\theta$ field is steady over Marseille from day to day. So the network must be designed to sample the south-west/north-east gradient. This spatial structure is also close to that of $\mathrm{EOF}_{1}^{q}$. This characteristic allows the simultaneous sampling of both spatial structures of $\mathrm{EOF}_{1}^{\theta}$ (day) and $\mathrm{EOF}_{1}^{q}$ with the same network, and thus to reduce the number of stations required.

The design of the network presented in Figure 13 is that finally chosen; first, a south-west/north-east axis (axis 1) is constituted of seven stations $(5,19,16,6,8,12$ and 11). This axis samples the decrease of temperature mentioned as $\mathrm{C}$ in Figure 11 and also the structure of the $\theta$ field during daytime (Figure 10) and $q$ (Figure 12). A second south-west/north-east axis (axis 2) with homogeneous urbanization includes four stations (1, 2, 3 and 10). Then two west-east axes are constituted: axis 3 is composed of five stations $(15,14,7,9$ and 10) and is designed to capture the organization of the field in the case of a westerly sea breeze. Axis 5 is parallel to axis 3 (to the south) and is composed of two stations (5 and 19) already defined and two other stations ( 3 and 4 ) that are set up in the area identified as $\mathrm{B}$ in Figure 11. Then one station is installed in the north of the domain to sample the D areas presented previously. This station completes axis 4, which is a north-south axis composed of five stations (13, 15, 19, 5 and 1). Finally, two stations (17 and 18) are located northward of the city old core to obtain a good representation of different zones of the most urbanized area.

\subsection{Evaluation of NETWORK DISPOSITION}

In order to verify that the chosen network disposition is able to capture the major characteristics of the thermodynamic patterns, the 20 locations of the network have been extracted from the simulation (average of the four closest grid points) and EOFs have been computed at these locations. The results are presented in Figure 14. The upper graphs show the first EOF for potential temperature during daytime, which captures $61 \%$ of the variance; it must be compared to Figure 10, which is the first EOF for the same parameter and period but for all the points of the simulation (see 

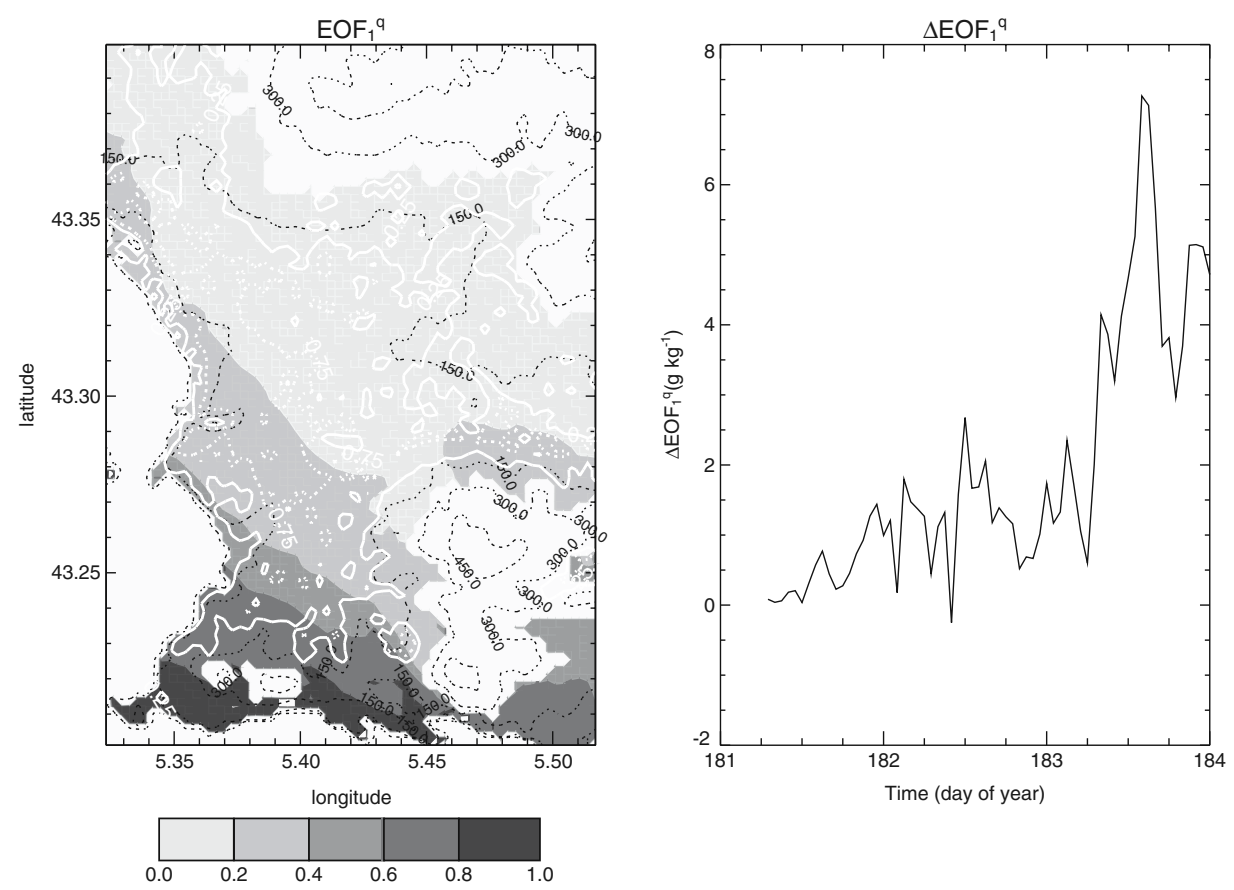

Figure 12. Same as Figure 10 but for $q$ (daytime and nighttime).

Section 4.1). This latter EOF captures $63 \%$ of the variance, so on this point the two EOFs are comparable. Then, the EOF computed on the 20 points of the network presents the same spatial and temporal characteristics as the one computed on all the points of the model grid. The spatial structure is dominated by a south-west to north-east gradient, and the temporal evolution has a day-to-day cycle with a peak around midday. The maxima reached are not the same in the two EOFs because the extreme points of the EOF computed on the whole fields are not exactly at the same place as those from the 20 stations of the network. The middle graphs of Figure 14 are the EOF computed on potential temperature during nighttime with the 20 points of the network. It must be compared to Figure 11, which is the EOF computed for the whole grid. The variances captured by these EOFs are also of the same order, with $72 \%$ for the EOF computed on the 20 points and $65 \%$ for the EOF computed on the whole grid. Then, the spatial structure shows a warm area on the west side of the domain (most urbanized area) and colder areas around. The time series associated with this structure also presents a recurring evolution during the nighttime evolution with an increase in the first part of the night and a decrease in the early morning. Finally, the bottom graphs present the EOF computed on the 20 points of the network extracted from the simulation for specific humidity over the whole period of the simulation. It must be compared 


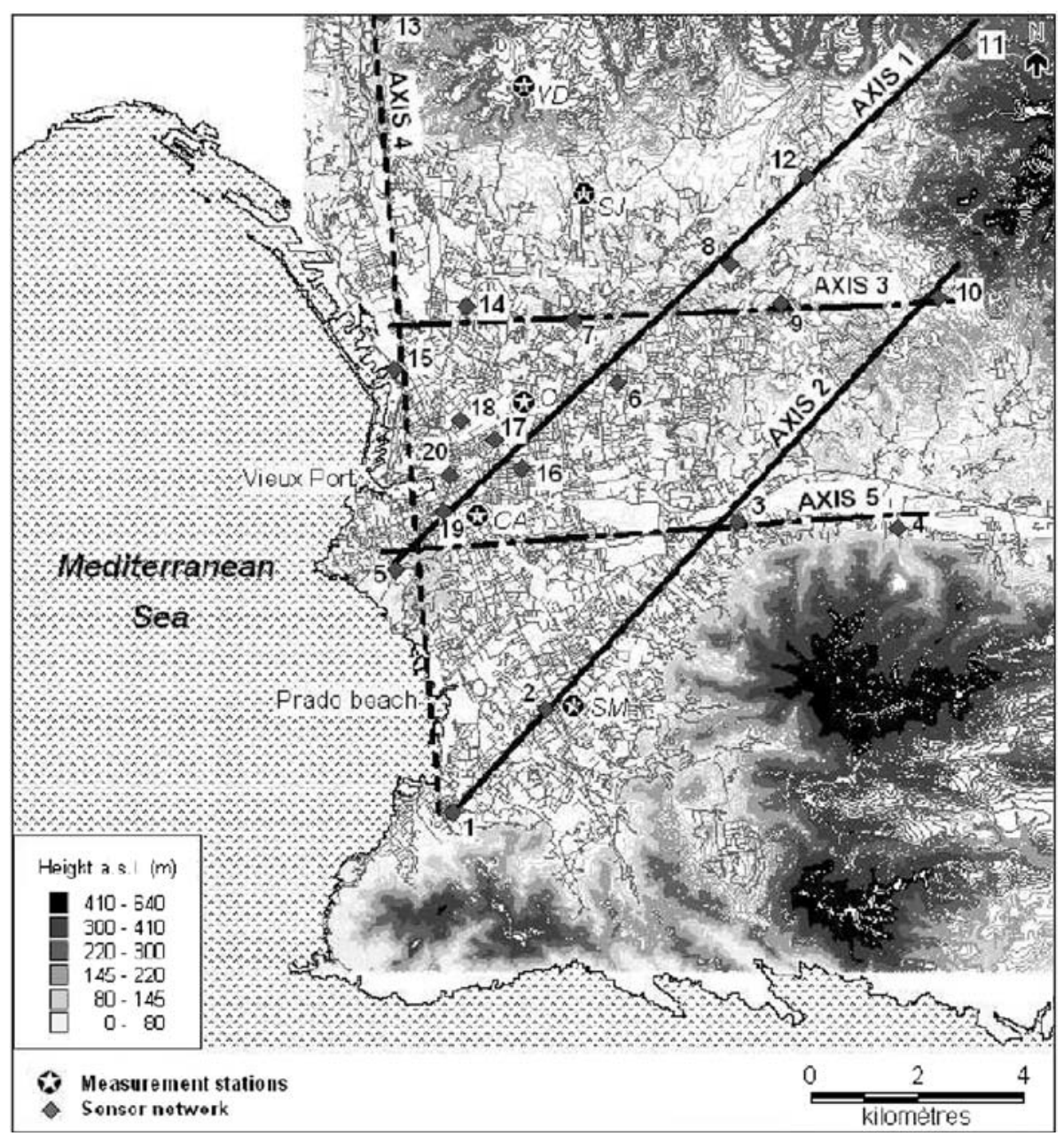

Figure 13. Map of the 20 sensors network (grey diamonds) and of wind and flux measurement stations (white stars in black disks). CA: Cours d'Appel, SJ: Saint Jérôme, SM: Sainte Marguerite, O: Observatoire and VD: Vallon Dol.

to Figure 12. Both EOFs capture about the same variance, with $46 \%$ for the EOF computed on the 20 points and $52 \%$ for the EOF computed over the complete grid. For both spatial patterns, one can note a north-east to south-west gradient of moisture; the temporal evolution moves towards an increase of spatial variability at the end of the period.

EOFs computed on the 20 points chosen for the network confirm the relevance of this disposition. The network is able to capture the major characteristics of the surface thermodynamic fields: (1) the south-west to north-east potential temperature gradient during the day associated with a maximum of spatial variability around midday; (2) the higher potential temperature 

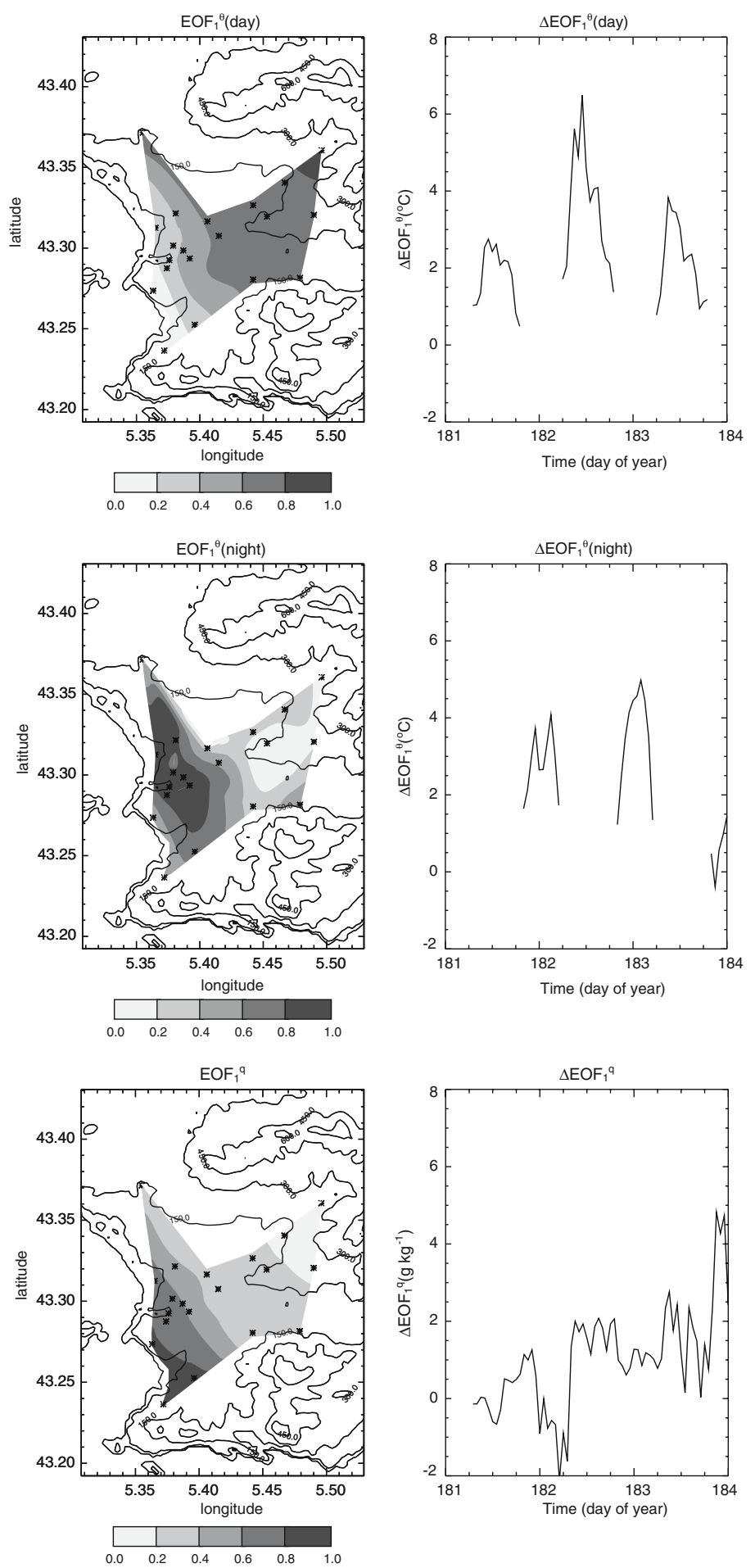
Figure 14. First EOFs computed on the 20 points of the network extracted from the simulation output for potential temperature during daytime (top), potential temperature during nighttime (middle) and specific humidity over the whole period (bottom). The black crosses indicate the 20 locations selected for the sensors.
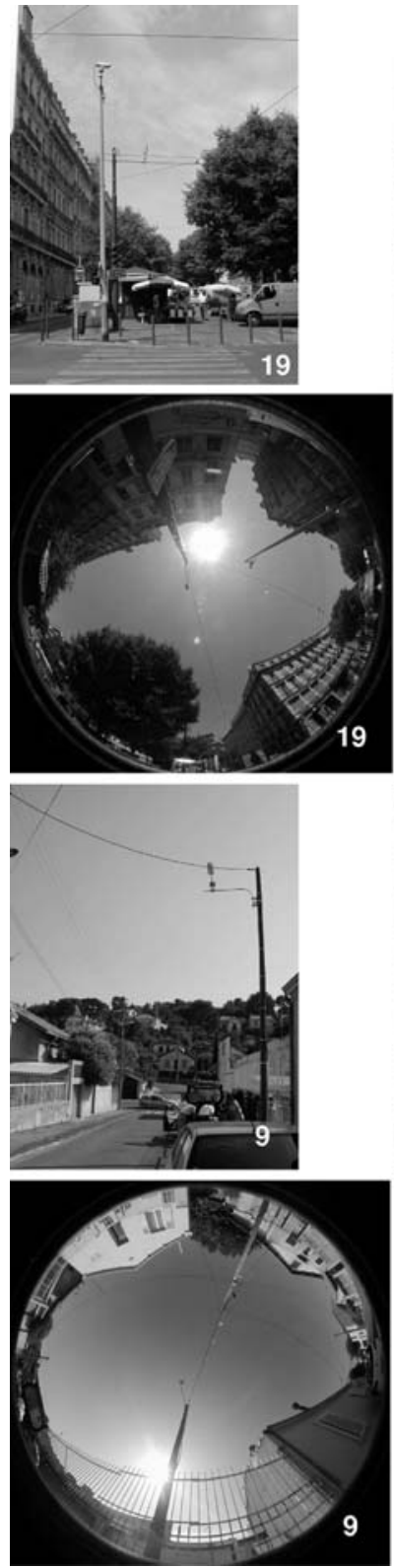
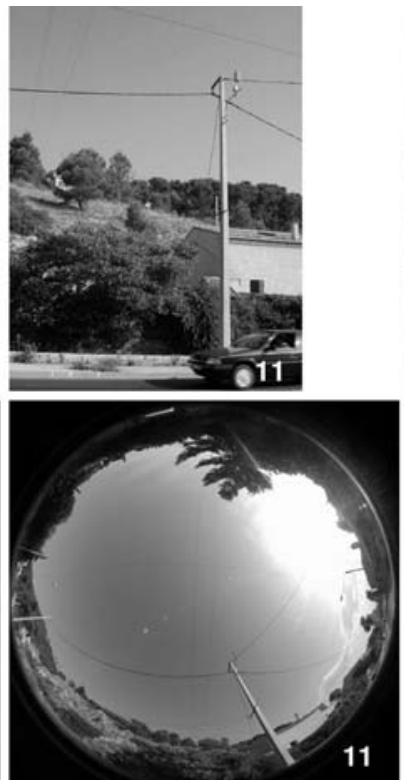

11
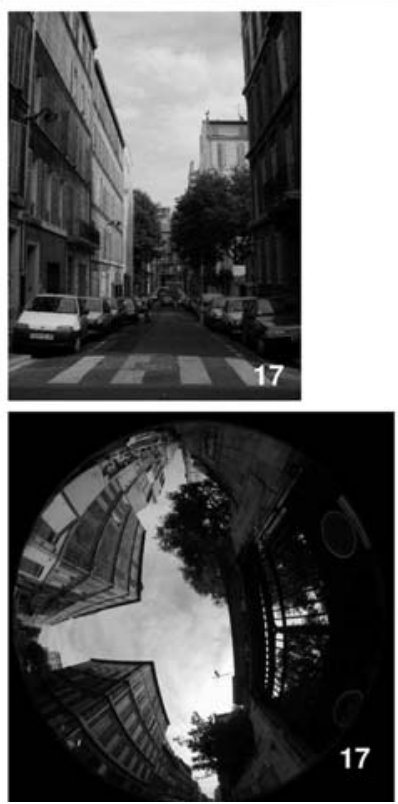
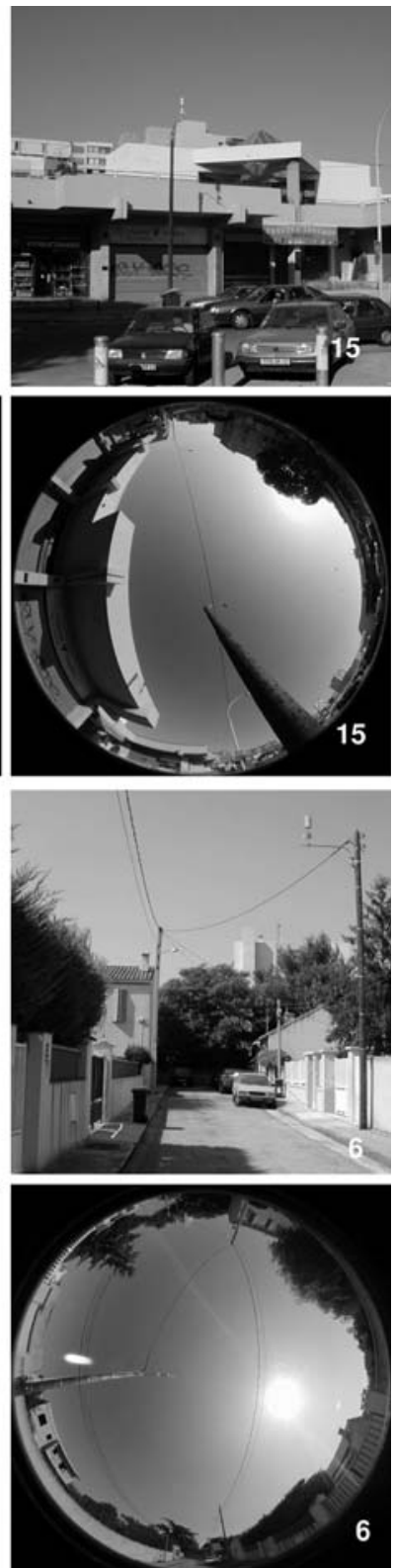

Figure 15. Photographs of a site for each of the six urban classes of Table II with conventional and fish-eye camera. The number of the sensor is indicated on each graph. 
over the most urbanized area during nighttime, and a temperature difference between this area and its surroundings that increases during the first part of night and then decreases as with a typical UHI; (3) the north-east to south-west gradient of specific humidity during the whole period.

\subsection{SENSOR SURROUNDINGS}

The 20 sensors were spread throughout the city centre, the suburbs, along the coast and close to the rural area, with the urban characteristics of the sensor surroundings (Table II) described with an urban database, the BDTopo produced from photogrammetry by the French National

TABLE II

Characteristics of sensor surroundings.

\begin{tabular}{|c|c|c|c|c|c|c|}
\hline & & $\begin{array}{l}\text { Building } \\
\text { p.a.d. }\end{array}$ & $\begin{array}{l}\text { Impervious } \\
\text { p.a.d. }\end{array}$ & $\begin{array}{l}\text { Spacing } \\
W(\mathrm{~m})\end{array}$ & $\begin{array}{l}\text { Building } \\
\text { height } \\
H(\mathrm{~m})\end{array}$ & $H / W$ \\
\hline \multirow[t]{2}{*}{ City centre } & Sensor 19 & 0.57 & 0.16 & 17.0 & 16.3 & 0.96 \\
\hline & Sensor 20 & 0.52 & 0.21 & 19.1 & 17.9 & 0.94 \\
\hline \multirow[t]{3}{*}{ Pericentre } & Sensor 16 & 0.49 & 0.17 & 15.2 & 13.0 & 0.86 \\
\hline & Sensor 17 & 0.46 & 0.16 & 24.1 & 15.3 & 0.63 \\
\hline & Sensor 18 & 0.40 & 0.17 & 28.0 & 15.2 & 0.54 \\
\hline \multirow[t]{2}{*}{ Indus area } & Sensor 14 & 0.22 & 0.12 & 38.1 & 10.0 & 0.26 \\
\hline & Sensor 15 & 0.36 & 0.19 & 35.0 & 11.7 & 0.33 \\
\hline \multirow[t]{2}{*}{ Res. bdgs } & Sensor 1 & 0.13 & 0.11 & 51.4 & 8.7 & 0.17 \\
\hline & Sensor 2 & 0.21 & 0.16 & 26.5 & 9.0 & 0.34 \\
\hline \multirow{4}{*}{$\begin{array}{l}\text { area } \\
\text { (high) }\end{array}$} & Sensor 3 & 0.21 & 0.14 & 38.6 & 9.1 & 0.24 \\
\hline & Sensor 5 & 0.23 & 0.11 & 23.2 & 7.8 & 0.34 \\
\hline & Sensor 6 & 0.22 & 0.11 & 22.2 & 6.8 & 0.31 \\
\hline & Sensor 7 & 0.22 & 0.15 & 29.0 & 9.9 & 0.34 \\
\hline \multirow{4}{*}{$\begin{array}{l}\text { Res. bdgs } \\
\text { area } \\
\text { (mean) }\end{array}$} & Sensor 4 & 0.10 & 0.07 & 49.8 & 5.0 & 0.10 \\
\hline & Sensor 9 & 0.12 & 0.11 & 46.5 & 9.0 & 0.19 \\
\hline & Sensor 12 & 0.14 & 0.10 & 40.1 & 6.9 & 0.17 \\
\hline & Sensor 13 & 0.12 & 0.10 & 41.3 & 6.7 & 0.16 \\
\hline \multirow{3}{*}{$\begin{array}{l}\text { Res. bdgs } \\
\text { (low) }\end{array}$} & Sensor 8 & 0.08 & 0.08 & 55.2 & 7.9 & 0.14 \\
\hline & Sensor 10 & 0.06 & 0.05 & 40.6 & 3.7 & 0.09 \\
\hline & Sensor 11 & 0.02 & 0.03 & 55.4 & 3.6 & 0.06 \\
\hline
\end{tabular}

Indus.: industrial; Res.: residential; bdgs: buildings; p.a.d.: plan area density. 
Geographic Institute. BDTopo contains information about surface cover such as buildings, vegetation, water surface, road network and elevation (a.s.1.) of the specified cover. This vectorial information was transformed in raster mode with a laboratory software DFMap (Long et al., 2002), which computes statistical variables onto a grid, describing the building morphology (height, perimeter, volume, compactness), the land-cover mode (building, vegetation, impervious, water plan area densities - p.a.d.) and the urban structure (building number per cell, spacing between the buildings). These variables are included in a geographic information system (GIS) with a cell size of $200 \mathrm{~m} \times 200 \mathrm{~m}$ (Long, 2003). From these GIS variables, a classification method (k-means) is applied to determine spatially and statistically the different districts of Marseille. The results are not presented here but the district outlines are drawn on Figure 1 (Long and Kergomard, 2005).

The surroundings of the sensors are characterized by the average of grid points inside a circle of $500 \mathrm{~m}$ radius around each location. The sensors 19 and 20 were in the city centre, where the building p.a.d. is the highest. This district is composed of buildings of 5-7 storeys height, disposed on a regular street network with orthogonal intersections and narrow streets. Vegetation is low, represented by public gardens or hedges along the main streets only.

Around the city centre, another district is identified: the peri-centre. Its urban structure is less regular, the buildings having a less compact form and the building p.a.d. is lower than in the city centre. The sensors 16, 17 and 18 were placed at the limit between these districts. The peri-centre is also comprised of industrial areas like the Delorme area, located to the north of the city centre. This area grouped the sensor 15 , close to the coast, the sensor 14 , and extended $2 \mathrm{~km}$ from the shoreline.

Other sensors were placed in residential building areas. These districts are defined by individual housing (1-2 storeys) with private gardens and a regular road network where the building p.a.d. is high. In the suburbs, the building p.a.d. decreases and the vegetation p.a.d. increases from the city centre to the rural area. So we can distinguish three levels of urbanization in the suburbs (three last classes of Table II):

- high building p.a.d. (sensors 1, 2, 3, 5, 6 and 7);

- medium building p.a.d. (sensors 4, 9, 12 and 13);

- low building p.a.d. (sensors 8, 10 and 11).

All the urban characteristics of the sensor surroundings are listed in detail in Table II and a photograph of one station for each class is presented in Figure 15. 


\section{Spatio-temporal Variability of Air Potential Temperature and Specific Humidity during the 2001 Field Campaign}

The measurements recorded by the network of 20 stations during the 2001 field campaign are now used to analyse the characteristics of the spatiotemporal variability of $\theta$ and $q$. Measured air temperature and relative humidity were converted to $\theta$ and $q$ using the pressure measurements at the Vallon Dol site (VD in Figure 13), and the hydrostatic law to compute the pressure at each site. Like the simulation, the measurements are analysed using the EOF method. The computation is performed over the 20 stations but the 4752 samples (record every 10 minutes during 33 days) of each parameter $(\theta$ and $q)$ are separated between nighttime (2000 UTC to 0600 UTC) and daytime (0600 UTC to 2000 UTC).

\subsection{Air POTENTIAL TEMPERATURE AT NightTIME}

For $\theta$ during nighttime, the spatial structure of $\mathrm{EOF}_{1}^{\theta}$ (night), which captures $67 \%$ of the total variability, presents concentric curves around the old city centre of Marseille (compare Figure 16a and Figure 1). The spatial variability is not as refined as for the simulation (see Figure 11 for example) because of the small number of stations (20) in comparison to the number of grid points of the simulation (7776). However, Figure 16 has merit since it gives an accessible visualization of the general pattern of the spatial variability. The time series of the EOF, $\triangle \mathrm{EOF}_{1}^{\theta}$ (night) (see Appendix A for precise definition), is presented in Figure 17a (upper graph). The first characteristic of this time series is its similar evolution from one night to another: $\triangle \mathrm{EOF}_{1}^{\theta}$ (night) tends to increase during the first part of the night and to decrease in the early morning. This is the typical evolution of the UHI during nighttime (Oke, 1987). The second characteristic of this time series is the variability of the maximum value reached during nighttime (from more than $5^{\circ} \mathrm{C}$ to less than $1^{\circ} \mathrm{C}$ ). This recurring nighttime variability is linked to the control of UHI intensity by meteorological factors such as wind or cloud cover. The time series of the wind speed, as well as the incoming shortwave and longwave radiation, measured at ground level at the Vallon Dol station (see Figure 1 for the location), are plotted on the same figure.

Since cloud cover fraction does not vary during the period (clear sky conditions are observed most of the time), it is not a determinant factor to explain the observed variability of the UHI maximum intensity. However, during moderate to strong wind events, $\Delta \mathrm{EOF}_{1}^{\theta}$ (night) has a weak variation and presents its lowest values. This is the case from 16 to 19 June, and for 28 June, 5, 6 and 7 July and 12 July. These observations are in agreement with Sundborg (1950), Morris et al. (2001) and Eliasson and 


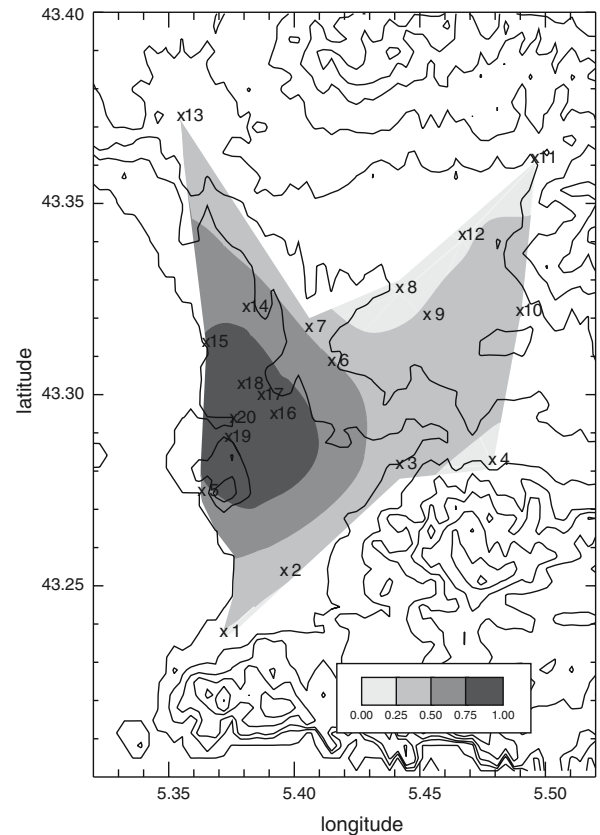

(a) $\theta$ during nighttime

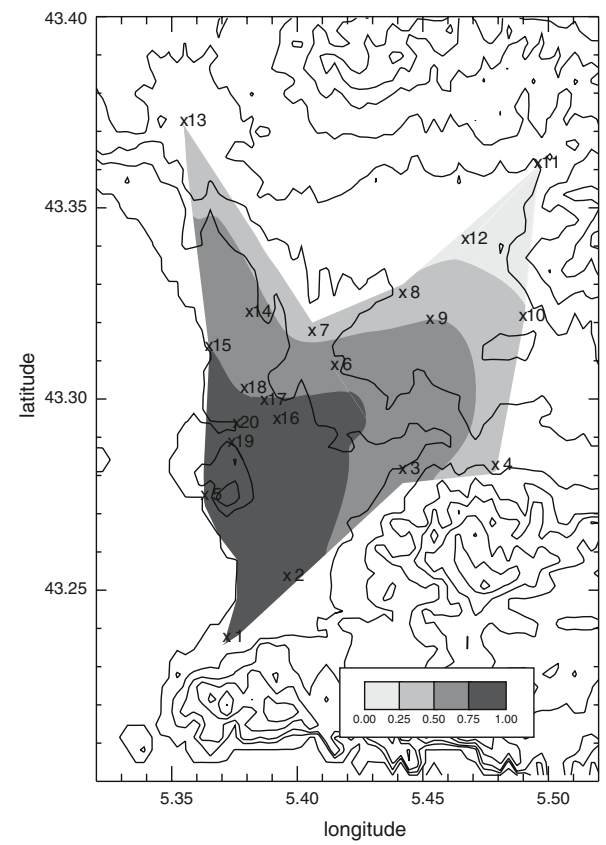

(c) $q$ during nighttime

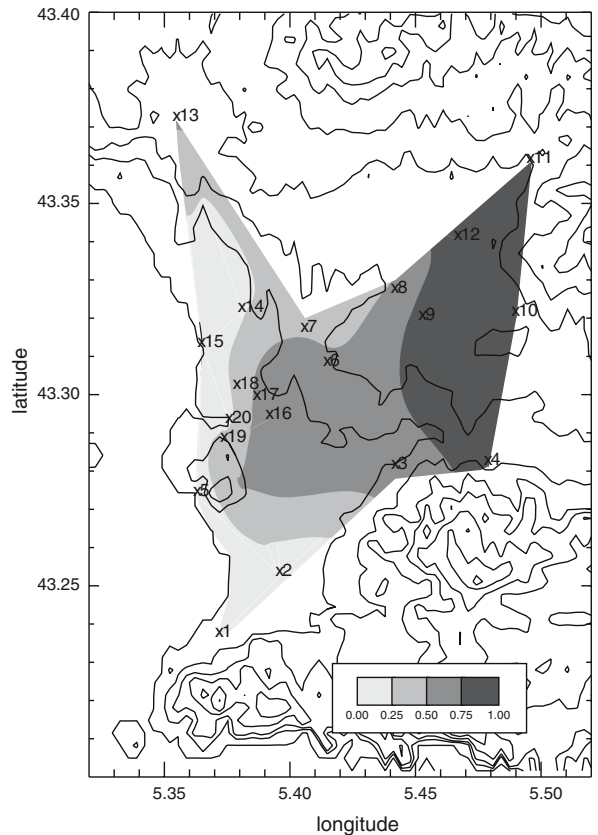

(b) $\theta$ during daytime

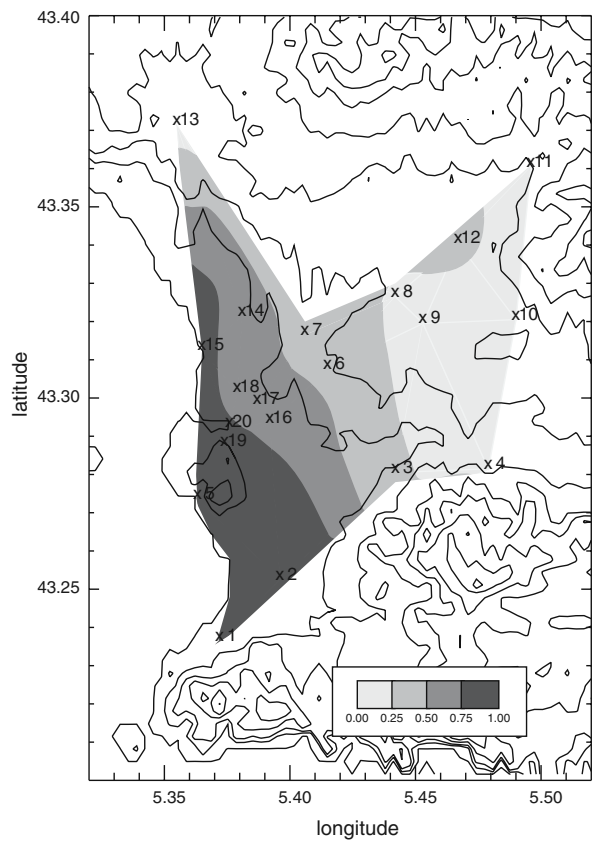

(d) $q$ during daytime

Figure 16. Fields of the normalized first EOF computed from observed air potential temperature and specific humidity for daytime and nighttime periods. 
(a) $\triangle \mathrm{EOF}_{1}{ }^{\theta}$ DURING NIGHTTIME

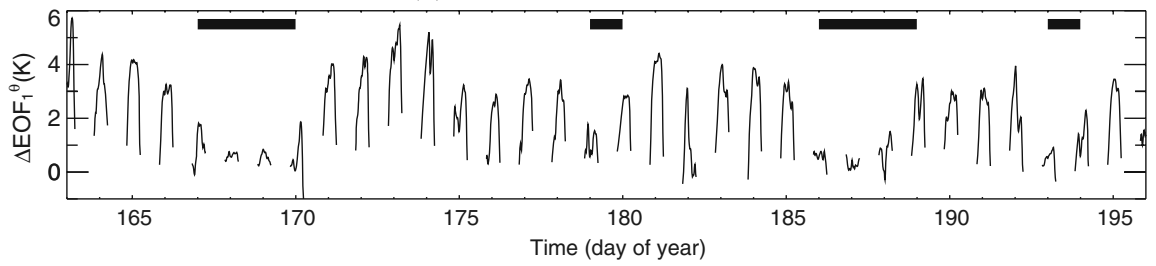

(b) $\triangle \mathrm{EOF}_{1}{ }^{\theta}$ DURING DAYTIME

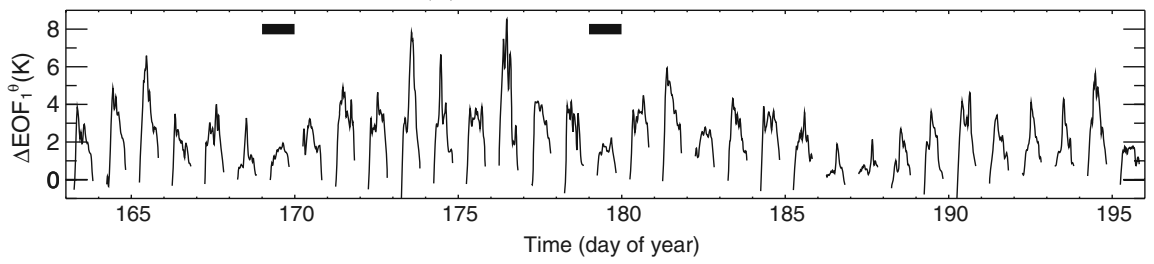

(c) $\triangle \mathrm{EOF}_{1}{ }^{a}$ DURING NIGHTTIME

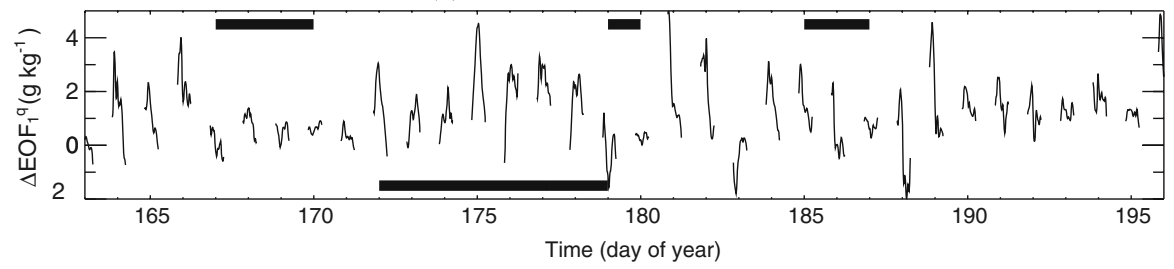

(d) $\triangle \mathrm{EOF}_{1}{ }^{a}$ DURING DAYTIME

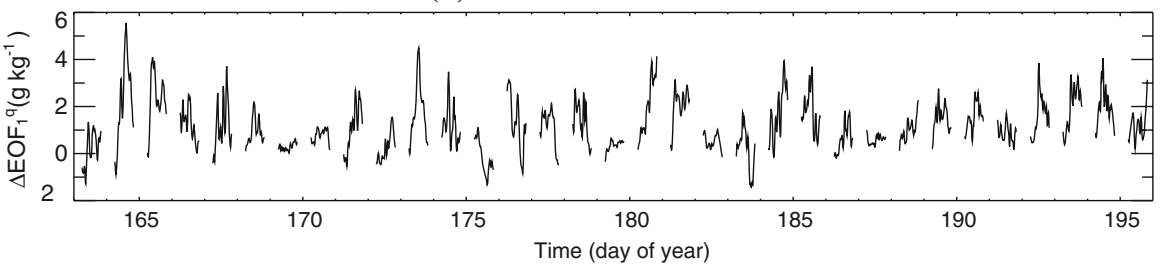

(e) WIND SPEED AT VALLON DOL

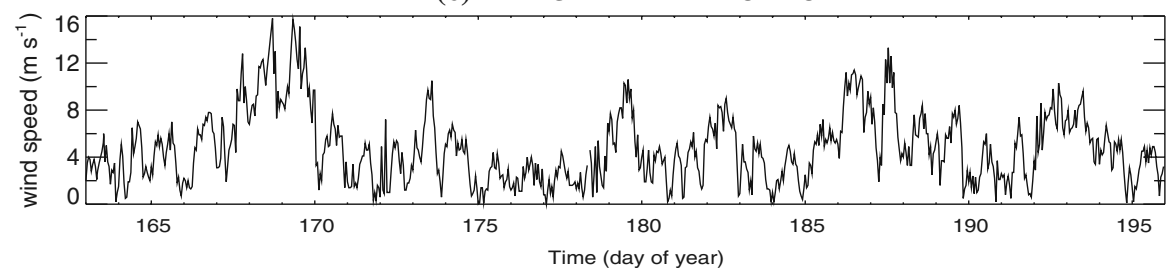

(f) INCOMING GLOBAL RADIATION AT VALLON DOL

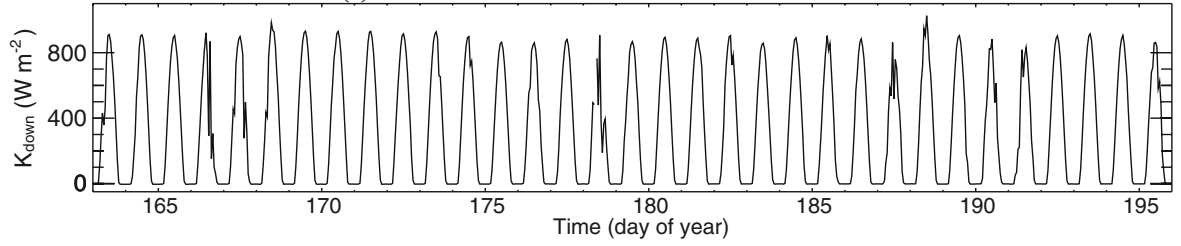


Figure 17. From top to bottom: time series of $\Delta \mathrm{EOF}_{1}^{\theta}$ (night), $\Delta \mathrm{EOF}_{1}^{\theta}$ (day), $\Delta \mathrm{EOF}_{1}^{q}$ (night), $\triangle \mathrm{EOF}_{1}^{q}$ (day), wind speed and incoming global radiation at Vallon Dol site (VD in Figure 13) for the 2001 campaign. Bold horizontal lines mark the periods analysed in more detail in the text.

Svensson (2003), and demonstrate the ability of the EOF method and the specific normalization used to study the UHI phenomenon.

\subsection{Air Potential temperature DURING DAYTime}

The behaviour of $\mathrm{EOF}_{1}^{\theta}$ (day) during daytime (63\% of the total variability) is completely different from that at night, the spatial variation is linked to the distance to the shoreline (Figure 16b). The corresponding time series, $\Delta \mathrm{EOF}_{1}^{\theta}$ (day), is presented in Figure $17 \mathrm{~b}$. When $\Delta \mathrm{EOF}_{1}^{\theta}$ (day) is positive, $\theta$ is higher over areas in the eastern part of the domain than over areas close the shoreline. Though we observe a variability of the value of the daily maximum, $\Delta \mathrm{EOF}_{1}^{\theta}$ (day) presents a repetitive shape of its diurnal evolution, translating as an increase of temperature difference between inland areas and coastal areas during the morning and a decrease during the afternoon. This evolution is linked to the sea breeze cycle that developed regularly over the region during the field campaign (Lemonsu et al., 2005). The days where the lowest maxima are observed correspond to low values of variability during the adjacent nights. This is the case for 18 and 28 June. During these 2 days, Mistral (north-west wind) winds are more than $10 \mathrm{~m} \mathrm{~s}^{-1}$. This is also the case for the 5 and 6 July during which winds from the south-east have speeds up to $10 \mathrm{~m} \mathrm{~s}^{-1}$. During these days the western sea breeze cannot develop and the temperature difference between the coastal and inland areas remains quite low.

\subsection{SPECIFIC HUMIDITY DURING NightTIME}

The first EOF captures $58 \%$ of the total variability, but the time series does not have a behaviour as simple as that for $\theta$ (Figure 17c): $q$ is higher in the south-west of the domain, which includes the city centre. The temporal evolution of $\Delta \mathrm{EOF}_{1}^{q}$ (night) is presented in Figure 17c. As for $\theta$, the cycle is weak when wind speed increases (see for example 16 to 19 June, 28 June, 4 and 5 July). Some days present a recurrent cycle, with an increase of $\Delta \mathrm{EOF}_{1}^{q}$ (night) during the first part of the night and then a decrease of the difference in $q$ between the south-west and the north-east areas. This is the case from 21 to 27 June during which a regular sea breeze cycle develops over the domain. 


\subsection{SPECIFIC HUMIdity DURING DAYTIME}

The first EOF captures $51 \%$ of the total variability and its horizontal field presents an organization parallel to the shoreline (Figure 16d) as for $\theta$ during daytime. The corresponding time series (Figure 17d) presents characteristics already described for other parameters, such as weak amplitude of the cycles during windy conditions and higher amplitudes when the sea breeze regime is well established.

\section{Relations between Thermodynamic Fields and Local Surface Characteristics}

In this section, the relations between thermodynamic fields and local surface characteristics are studied with both the observations and the simulation. This step allows us to evaluate the validity of the method and more specifically the ability of the model to reproduce these relations. It also allows us to evaluate the stability of the relations from year to year since the periods of the simulation and observations are not synchronous and of the same length (three days of summer 2000 for simulation and 33 days of summer 2001 for observations). In order to make the observations and the simulation comparable for the spatial patterns, the thermodynamic fields are characterized in the simulation with EOFs computed on the 20 points of the network as in Section 4.4.

\subsection{RELATION BETWEEN SPATIAL STRUCTURE OF $\theta$ DURING NIGHTTIME AND GEOGRAPHIC CHARACTERISTICS}

The spatial structure of temperature during nighttime depends on surface characteristics and especially on the urban structure of an agglomeration. The warmest areas of a city are generally those with the highest urban cover fraction (sum of buildings p.a.d. and roads p.a.d.) (Park, 1986; Nuñez et al., 2000; Unger et al., 2001; Eliasson and Svensson, 2003). They are generally characterized by high aspect ratios (height of street/width of street, $H / W$ ) or low sky view factor (Oke, 1981; Bärring and Mattson, 1985, Eliasson, 1996; Goh and Chang, 1999; Nuñez et al., 2000; Eliasson and Svensson, 2003). Such relations have been investigated for the first EOFs spatial structure on both observations and the simulation. The results are presented in Figure 18: average values and standard deviations have been computed for bins (of $H / W$ or urban cover fraction) of 0.2 . This figure exhibits a clear relationship between $\mathrm{EOF}_{1}^{\theta}$ (night) and both the urban cover fraction and the aspect ratio. Furthermore, this relation is similar when deduced from the observations or from the simulation (although for the relation with urban cover fraction, the correlation coefficient (see Table III) is slightly higher for observations than for the simulation). 
(a) Temperature during nighttime

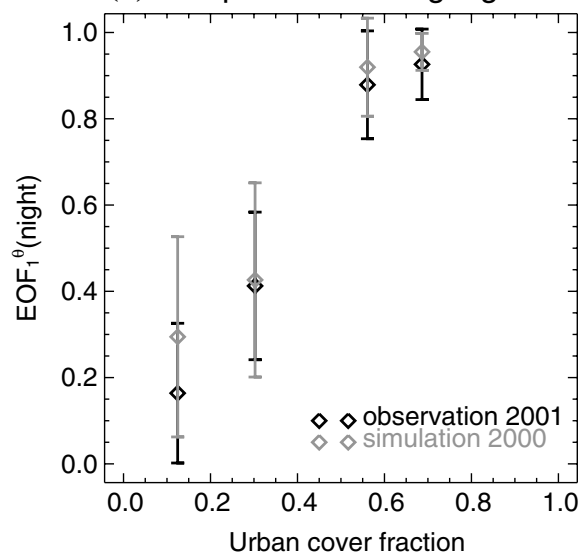

(b) Temperature during nighttime

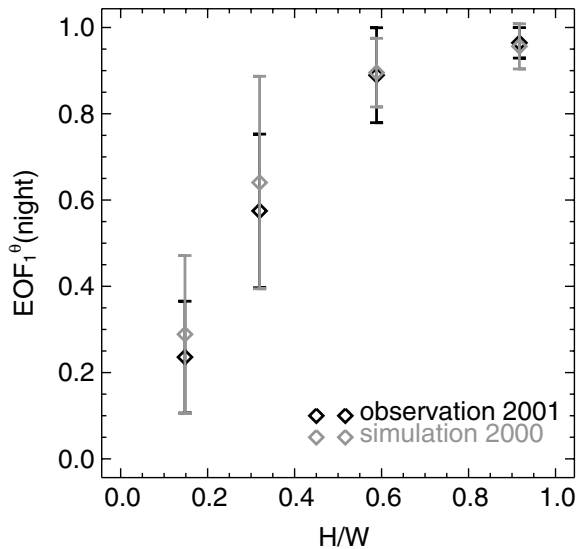

Figure 18. Relation between first EOF of $\theta$ during nighttime and urban cover fraction (left) or aspect ratio (right) deduced from the simulation (grey symbols) or observations (black symbol). Vertical bars indicate variability in each bin of urban cover or $H / W$.

\subsection{Relation BETWEen SPATIAL STRUCTURE of $\theta$ DURING DAYTIME AND GEOGRAPHIC CHARACTERISTICS}

Observations and the simulation of the spatial variability of $\theta$ during daytime have also been related to local parameters. In the literature, no

\section{TABLE III}

Percentage of variance explained by first EOFs and correlation coefficients $(\rho)$ between EOFs computed on observations or simulations and different geographic characteristics of the sites.

\begin{tabular}{|c|c|c|c|}
\hline & $\theta_{\text {night }}$ & $\theta_{\text {day }}$ & $q$ \\
\hline$\%$ variance obs & 67 & 63 & 51 \\
\hline$\%$ variance sim & 72 & 61 & 46 \\
\hline$\rho(\mathrm{obs}, \mathrm{sim})$ & 0.79 & 0.87 & 0.94 \\
\hline$\rho(\mathrm{obs}, \mathrm{UC})$ & 0.91 & -0.52 & 0.74 \\
\hline$\rho(\operatorname{sim}, \mathrm{UC})$ & 0.85 & -0.52 & 0.56 \\
\hline$\rho(\mathrm{obs}, H / W)$ & 0.86 & -0.37 & 0.66 \\
\hline$\rho(\operatorname{sim}, H / W)$ & 0.76 & -0.42 & 0.49 \\
\hline$\rho(\mathrm{obs}, \mathrm{dws})$ & -0.68 & 0.90 & -0.91 \\
\hline$\rho(\operatorname{sim}, \mathrm{dws})$ & -0.71 & 0.85 & -0.87 \\
\hline
\end{tabular}

obs: observation; sim: simulation; $H / W$ : aspect ratio; UC: Urban cover fraction; dws: distance to west shoreline. 
relation has been demonstrated between temperature during daytime and the characteristics of the urban structure. In the case of Marseille, as presented in the preceding sections, the spatial variability of temperature during daytime is completely different from that during nighttime. As can be seen in Figure 19 and Table III, the correlation coefficient between $\mathrm{EOF}_{1}^{\theta}$ (day) and urban cover fraction is quite low and even negative, with similar values for observations and the simulation. Even though no relation exists between the daytime spatial structure of $\theta$ and urban characteristics, the spatial structure, however, is quite steady at this period of the year, since it is observed for two consecutive years. Since the sea breeze often flows from the west over Marseille during summer, we have compared the relation between the daytime spatial structure of $\theta$ and distance to the west shoreline, for observations and the simulation. The results are presented in the right graph of Figure 19. Average values and standard deviations are computed for bins of distance to the shoreline of $2.5 \mathrm{~km}$. The corresponding correlation coefficients are presented in Table III: they are high for both observations and the simulation. The sea breeze is thus the driving parameter of the temperature field during daytime, which explains why its structure is reproduced from 1 year to the next.

\subsection{Relation Between SPATIAl STRUCTURE OF $q$ AND GEOGRAPHIC CHARACTERISTICS}

Finally, the same comparisons have been conducted for the spatial structure of specific humidity. For this case, since the difference of structure between

(a) Temperature during daytime

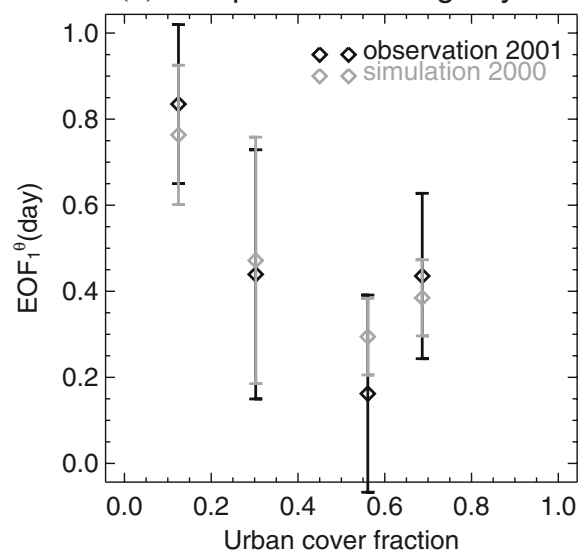

(b) Temperature during daytime

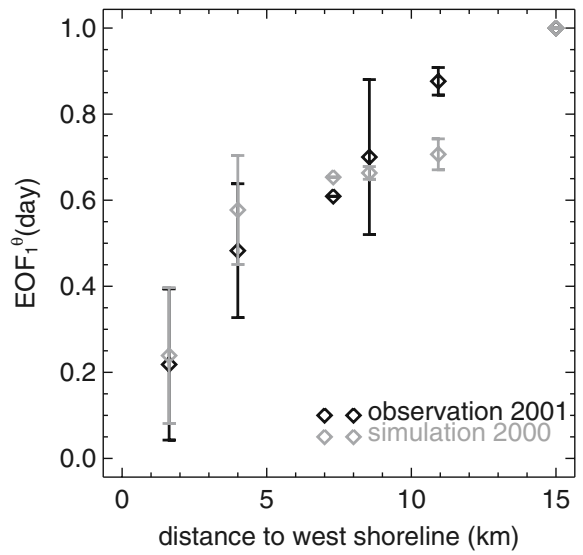

Figure 19. Relation between first EOF of $\theta$ during daytime and urban cover fraction (left) or distance to the west shoreline of the domain (right), deduced from the simulation (grey symbols) or observations (black symbols). Vertical bars indicate variability in each bin of urban cover or distance to the west shoreline. 
day and night is weak (see preceding sections), the spatial structures have been computed from observations and the simulation for the whole continuous period. As with the preceding section, the results are presented in the form of the relationships between the first EOF and urban cover fraction, or distance to the shoreline (Figure 20 and Table III). The highest (negative) correlations are observed between EOF and the distance to the shoreline, which seems reasonable. Regarding the relationship between EOF and urban cover fraction, the result is quite surprising, with a positive correlation (i.e. water content would increase with urbanization). However, the values of the correlation coefficient are not high (mainly for the simulation), and this relationship probably results from the fact that, in Marseille, the most urbanized areas are close to the shoreline. The distance to the west shoreline and urban cover fraction are therefore not independent.

\section{Conclusions}

The two main objectives of this study were first to optimize the set-up of an instrumented urban network (20 stations) measuring air temperature and relative humidity over the agglomeration of Marseille (France), and then to analyse the spatio-temporal variability of these fields retrieved from the measurements. We have adopted a strategy based on the following steps: (1) a high resolution numerical simulation was performed for a period of the preparatory field campaign (2000) using a specific parametrization for the urban surface energy balance; (2) carrying out an evaluation of this simulation against the available observation dataset; (3) performing

(a) Specific humidity

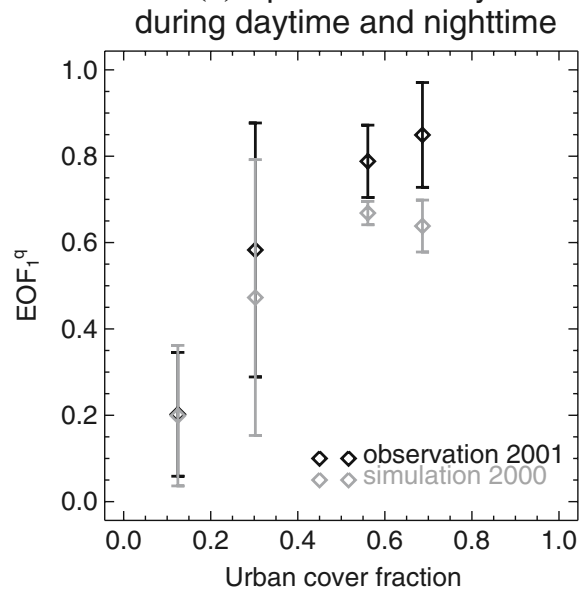

(b) Specific humidity during daytime and nighttime

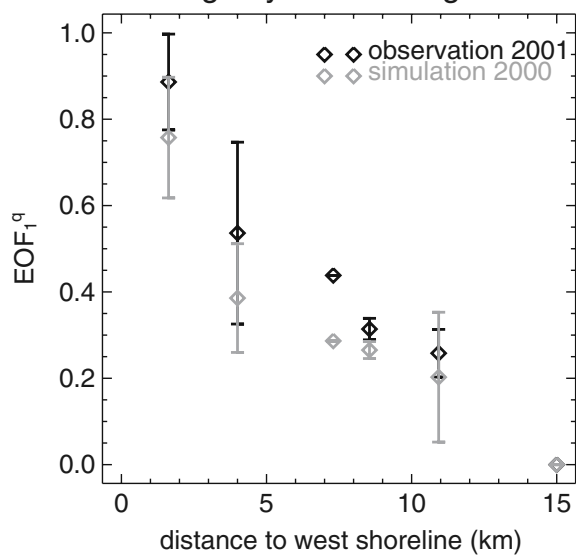

Figure 20. Same as Figure 19 but for $q$ during daytime and nighttime. 
an analysis of the output of this simulation with a specific normalization of EOF decomposition; (4) using the definition of the network disposition; (5) verifying that this disposition was able to retrieve the major characteristics of the fields by extracting the 20 selected locations from the simulation output and studying the spatio-temporal variability given by these points; (6) performing a spatio-temporal analysis of temperature and moisture fields using EOF decomposition; (7) analysing the relation between the spatial variability of the fields and the geographic characteristics.

The methodology of optimization of the network disposition, based on the numerical simulation and EOF decomposition, has proved to be efficient even though it is the first attempt of such a methodology in the field of urban meteorology. Despite the limited number of locations of the network, we were able to capture the major characteristics of the spatiotemporal variability of temperature and moisture over the agglomeration. In this method, the use of EOF decomposition with an adapted normalization has proved to be a powerful tool for studies of the urban thermodynamic island. We can deduce from this decomposition the spatial pattern of most of the variance and its temporal cycles. This technique, after being used for determination of network disposition, has been applied to the observations conducted in June and July 2001. We have presented evidence that the temperature field during nighttime over Marseille was dominated by the influence of the land-use, whereas during daytime it was influenced by the regular sea breeze cycles that develop during summer. Concerning moisture, the sea and local circulations are the main controlling factors. Over Marseille and during summer, urbanization does not seem to influence the spatio-temporal variability of moisture. Finally, a high correlation of the spatial patterns extracted from the EOF with urbanization characteristics (urban cover fraction or aspect ratio) has been found for temperature during nighttime. This relation has been shown from both the simulation of the summer 2000 and the measurements made in 2001.

Our study has demonstrated the value of using a high resolution numerical model, including a specific parametrization of the surface energy balance, to define an experimental device deployed in an extended urban area. The use of EOF decomposition on a network of limited instrumented sites (20), or on a simulation with a large number of points, has proved to be efficient in retrieving spatio-temporal patterns of high variability associated with an urban heat island.

\section{Acknowledgements}

The help of Dr. O. Mestre (Météo-France, France) concerning the use of the EOF decomposition is gratefully acknowledged. The authors would like to thank Dr. J. Salmond for his reading of the manuscript, the $4 \mathrm{M}$ team 
from the Centre National de Recherches Mététorologiques for preparation of the instruments and Dr. P.G. Mestayer for leading the UBL project. The UBL project has been funded by the French scientific program PATOM.

\section{Appendix: A Specific Normalization of EOF Results}

We apply the EOF method on two-dimensional data $X_{t, s}$ that are functions of time $(t)$ and space $(s) ; X$ is either $\theta$ or $q$. For EOF analysis applied to simulation output, there are 66 hourly fields of 7776 points (spatial grid of $72 \times 108$ ). For EOF analysis applied to observations, time series are composed of 4752 records (one value every 10 min during 33 days) for each of the 20 stations.

First of all, we centre $X_{t, s}$ by subtracting the mean diurnal cycle averaged over $N_{s}$ values, where $N_{s}$ equals either 7776 (grid points of the modelled field) or 20 (stations of the field measurements):

$$
X_{t, s}^{c}=X_{t, s}-\overline{X_{t}},
$$

where

$$
\overline{X_{t}}=\frac{1}{N_{s}} \sum_{s=1}^{N_{s}} X_{t, s} .
$$

The EOF method gives a new decomposition of $X_{t, s}^{c}$ :

$$
X_{t, s}^{c}=\sum_{k=1}^{N_{s}} S_{k}(s) T_{k}(t) .
$$

Each component $k$ is associated with the $k$ th eigenvalue (in descending order) of the variance-covariance matrix, $\underline{X}^{c} X^{c}\left(\underline{X}^{c}\right.$ is the transposed matrix); $S_{k}$ is the eigenvector associated with the $k$ th eigenvalue and gives the spatial structure of the component; $T_{k}$ is the time series of this spatial structure computed as: $T_{k}=X^{c} S_{k}$. In general $S_{k}$ are presented as the normalized vector $\left(\| S_{k}||=1\right)$ and as a consequence $T_{k}$ are affected by this normalization and represent the variation associated with the entire $S_{k}$ field. The interpretation of $T_{k}$ would be easier if $T_{k}$ could represent for example the difference between the two most contrasted points of the $S_{k}$ field. To cope with this problem we have computed another normalization, and the results that are presented in the paper are from

$$
\operatorname{EOF}_{k}^{X}(s)=\frac{S_{k}(s)-\operatorname{Min}\left(S_{k}\right)}{\operatorname{Max}\left(S_{k}\right)-\operatorname{Min}\left(S_{k}\right)}
$$

for the spatial structure and 


$$
\Delta \operatorname{EOF}_{k}^{X}(t)=T_{k}(t)\left(\operatorname{Max}\left(S_{k}\right)-\operatorname{Min}\left(S_{k}\right)\right)
$$

for the temporal evolution.

In this notation, suffix $k$ refers to the EOF and $X$ refers to the meteorological parameter $(\theta$ or $q)$. With this normalization, $0 \leq \operatorname{EOF}_{k}^{X}(s) \leq 1$, and $\Delta \mathrm{EOF}_{k}^{X}(t)$ gives the time series, in physical units of $\mathrm{K}$ for $\theta, \mathrm{g} \mathrm{kg}^{-1}$ for $q$, of the difference between the two most contrasted points of $k$ th function (these points have respective values 0 and 1 of $\mathrm{EOF}_{k}^{X}$ ). If $j$ is the value of $s$ for which $\operatorname{EOF}_{k}^{X}(j)=0$, for each $s \neq j$, the product $\operatorname{EOF}_{k}^{X}(s) \Delta \operatorname{EOF}_{k}^{X}(t)$ is the time series of $\triangle \mathrm{EOF}_{k}^{X}$ between the point $s$ and the point $j$ contained in the $k$ th function.

\section{References}

Arnfield, A. J.: 2003, 'Two Decades of Urban Climate Research: A Review of Turbulence, Exchanges of Energy and Water, and the Urban Heat Island', Int. J. Climatol. 23, 1-26. Bärring, L. and Mattson, J. O.: 1985, 'Canyon Geometry, Street Temperatures and Urban Heat Island in Malmö, Sweden', J. Climatol. 5, 433-444.

Bénech, B., Cachier, H., Cros, B., Durand, P., Gizard, E., Hanuise, C., Jambert, C., Lefebvre, M. P., Leopold, A., Lopez, A., Masclet, P., Penazzi, G., Robin, D., Saïd, F., Serça, D., Sol, B., and Zephoris, M.: 2001, 'Report of ESCOMPTE preparatory field campaign - 19 June-9 July 2000'. Technical report, Laboratoire d'Aérologie, 14 avenue Edouard Belin 31400 Toulouse, FRANCE. In French, 152 pp., available on request from the authors.

Bougeault, P. and Lacarrère, P.: 1989, 'Parametrization of Orography-induced Turbulence in a Meso-beta-scale Model', Mon. Wea. Rev. 117, 1872-1890.

CEC: 2000, 'CORINE Land Cover. Technical guide, Addendum', Technical Report 40, European Environment Agency.

Cros, B., Durand, P., Cachier, H., Drobinski, P., Fréjafon, E., Kottmeïer, C., Perros, P. E., Peuch, V. H., Ponche, J. L., Robin, D., Saï, F., Toupance, G., and Wortham, H.: 2004, 'The ESCOMPTE Program: An Overview', Atmos Res. 69, 241-279.

Cuxart, J., Bougeault, P., and Redelsperger, J. L.: 2000, 'A Turbulence Scheme Allowing for Mesoscale and Large-eddy Simulations', Quart. J. Roy. Meteorol. Soc. 126, 1-30.

Deardorff, J. W.: 1970, 'A Three-dimensional Numerical Study Investigation of the Idealized Planetary Boundary Layer', Geoph. Fluid Dyn. 27, 377-410.

Dupont, S., Otte, T. L., and Ching, J. K. S.: 2004, 'Simulation of Meteorological fields within and above Urban and Rural Canopies with a Mesoscale Model', Boundary Layer Meteorol. 113(1), 111-158.

Eliasson, I.: 1996, 'Urban Nocturnal Temperatures, Street Geometry and Land Use', Atmos. Environ. 30, 379-392.

Eliasson, I. and Svensson, M. K.: 2003, 'Spatial Air Temperature Variations and Urban Land Use - a Statistical Approach', Meteorol. Appl. 10, 135-149.

Goh, K. C. and Chang, C. H.: 1999, 'The Relationship between Height to Width Ratios and the Heat Island Intensity at 22:00 h for Singapore', Int. J. Climatol. 19, 1011-1023.

Hage, K. D.: 1975, 'Urban-Rural Humidity Differences', J. Appl. Meteorol. 14, 1277-1283.

Holmer, B. and Eliasson, I.: 1999, 'Urban-Rural Vapour Pressure Differences and their Role in the Development of Urban Heat Islands', Int. J. Climatol. 19, 989-1009. 
Kessler, E.: 1969, 'On the Distribution and Continuity of Water Substance in Atmospheric Circulation', Meteorol. Monog. 10, 1-84.

Lafore, J. P., Stein, J., Asencio, N., Bougeault, P., Ducrocq, V., Duron, J., Fischer, C., Héreil, P., Mascart, P., Masson, V., Pinty, J. P., Redelsperger, J. L., Richard, E. and de Arellano, J. V.-G.: 1998, 'The Méso-NH Atmospheric Simulation System. Part I: Adiabatic Formulation and Control Simulation', Ann. Geophys. 16, 90-109.

Lemonsu, A. and Masson, V.: 2002, 'Simulation of a Summer Urban Breeze over Paris', Boundary-Layer Meteorol. 104, 463-490.

Lemonsu, A., Grimmond, C. S. B. and Masson, V.: 2004, 'Modeling the Surface Energy Balance of the Core of an Old Mediterranean City: Marseille', J. Appl. Meteorol. 43, 312327.

Lemonsu, A., Pigeon, G., Masson, V. and Moppert, C.: 2005, 'Sea-town Interactions over Marseille: 3D Urban Boundary Layer and Thermodynamic Fields near the Surface', Theor. Appl. Climatol. 74(2), 1-12.

Lemonsu, A., Bastin, S., Masson, V. and Drobinski, P.: 2006, 'Vertical Structure of the Urban Boundary Layer over Marseille under Sea breeze Conditions', Boundary-Layer Meteorol., 118, xx-xx.

Long, N.: 2003, 'Analyses Morphologiques et Aérodynamiques du tissu urbain: application à la micro-climatologie de Marseille pendant la campagne ESCOMPTE'. Ph.D. Thesis (in French), Université des Sciences et Techniques de Lille, France.

Long, N. and Kergomard, C.: 2005, 'Classification Morphologique du tissu urbain pour des applications climatologiques', Revue Internationale de Géomatique, in press.

Long, N., Mestayer, P. and Kergomard, C.: 2002, 'Development of a Software to Describe the City Morphology and to Compute Aerodynamic Parameters from an Urban Data Base', in Fourth Symp. on the Urban Environment, Norfolk, VA, American Meteorological Society, Boston, MA, pp. 31-32.

Martilli, A., Clappier, A. and Rotach, M. W.: 2002, 'An Urban Surface Exchange Parameterisation for Mesoscale Models', Boundary Layer Meteorol. 104(2), 261-304.

Masson, V.: 2000, 'A Physically-based Scheme for the Urban Energy Budget in Atmospheric models', Boundary-Layer Meteorol. 94, 357-397.

Masson, V., Champeaux, J. L., Chauvin, F., Meriguet, C. and Lacaze, R.: 2003, 'A Global Data Base of Land Surface Parameters at $1 \mathrm{~km}$ Resolution in Meteorological and Climate Models', J. Climate 16, 1261-1282.

Masson, V., Grimmond, C. S. B. and Oke, T. R.: 2002, 'Evaluation of the Town Energy Balance (TEB) Scheme with Direct Measurements from Dry Districts in Two Cities', J. Appl. Meteorol. 41, 1011-1026.

Mestayer, P. G., Durand, P., Augustin, P., Bastin, S., Bonnefond, J. M., Bénech, B., Campistron, B., Coppalle, A., Delbarre, H., Dousset, B., Drobinski, P., Druilhet, A., Fréjafon, E., Grimmond, C. S. B., Groleau, D., Irvine, M., Kergomard, C., Kermadi, S., Lagouarde, J. P., Lemonsu, A., Lohou, F., Long, N., Masson, V., Moppert, C., Noilhan, J., Offerle, B., Oke, T. R., Pigeon, G., Puygrenier, V., Roberts, S., Rosant, J. M., Saïd, F., Salmond, J., Talbaut, M., and Voogt, J.: 2005, 'The Urban Boundary-Layer Field Campaign in Marseille (UBL/CLU-Escompte): Set-Up and First Results', Boundary-Layer Meteorol. 114, 315-365.

Morcrette, J. J.: 1991, 'Radiation and Cloud Radiative Properties in the European Center for Medium Range Weather Forecasts Forecasting System', J. Geophys. Res. 96, 9121-9132.

Morris, C. J. G., Simmonds, I., and Plummer, N.: 2001, 'Quantification of the Influences of Wind and Cloud on the Nocturnal Urban Heat Island of a Large City', J. Appl. Meteorol. 40, 169-182. 
Nakamura, Y. and Oke, T. R.: 1988, 'Wind, Temperature and Stability Conditions in an East-west Oriented Urban Canyon', Atmos. Environ. 22, 2691-2700.

Noilhan, J. and Mahfouf, J. F.: 1996, 'The ISBA Land Surface Parameterisation Scheme', Global Planetary Change 13, 145-159.

Noilhan, J. and Planton, S.: 1989, 'A Simple Parameterization of Land Surface Processes for Meteorological Models', Mon. Wea. Rev. 117, 536-549.

Nuñez, M., Eliasson, I., and Lindgren, J.: 2000, 'Spatial Variations of Incomming Longwave Radiation in Göteborg, Sweden', Theor. Appl. Climatol. 67, 181-192.

Oke, T. R.: 1981, 'Canyon Geometry and the Nocturnal Urban Heat Island: Comparison of Scale Model and Field Observations', Int. J. Climatol. 1, 237-254.

Oke, T. R.: 1987, Boundary Layer Climates, Methuen, London and New York, pp. 435.

Oke, T. R.: 2004, 'Urban Observations', IOM report, World Meteorological Organization, Geneva. 49 pp.

Park, H. S.: 1986, 'Features of the Heat Island in Seoul and its Surrounding Cities', Atmos. Environ. 20, 1859-1866.

Sundborg, A.: 1950, 'Local Climatological Studies of the Temperature Conditions in an Urban Area', Tellus 2(3), 221-231.

Unger, J., Sümeghy, Z., Gulyás, Á., Bottyán, Z. and Mucsi, L.: 2001, 'Land-use and Meteorological Aspects of the Urban Heat Island', Meteorol. Appl. 8, 189-194.

Vihma, C. and Kottmeier, C.: 2000, 'A Modelling Approach for Optimizing Flight Patterns in Airbone Meteorological Measurements', Boundary-Layer Meteorol. 95, 211-230. 